For Table of Contents Use Only

\title{
Cellulose Triacetate Doped with Ionic Liquids for Membrane Gas Separation
}

Benjamin $\mathrm{Lam}^{1}$, Min Wei ${ }^{1}$, Lingxiang Zhu ${ }^{1}$, Shuangjiang $\mathrm{Luo}^{2}$, Ruilan $\mathrm{Guo}^{2}$, Atsushi Morisato ${ }^{3}$, Paschalis Alexandridis ${ }^{1}$, and Haiqing $\operatorname{Lin}^{1}{ }^{1} *$

Table of Contents (TOC) Graphic

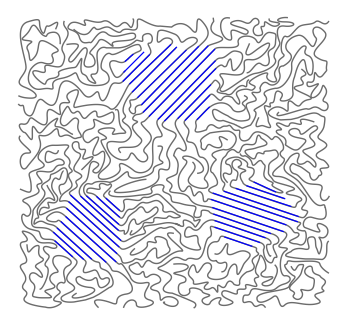

CTA only 2 domains
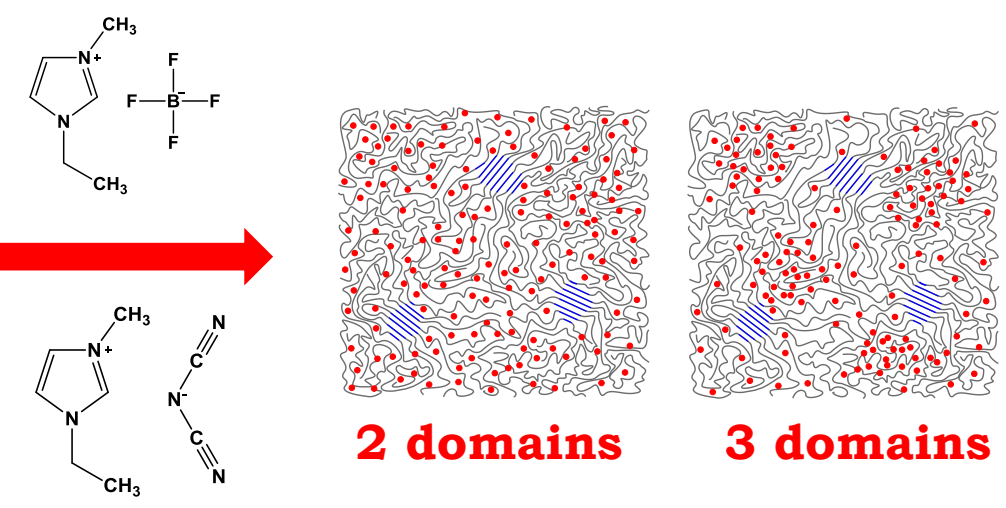


\section{Cellulose Triacetate Doped with Ionic Liquids for Membrane Gas Separation}

Benjamin $\mathrm{Lam}^{1}$, Min $\mathrm{Wei}^{1}$, Lingxiang Zhu ${ }^{1}$, Shuangjiang Luo ${ }^{2}$, Ruilan Guo ${ }^{2}$, Atsushi Morisato ${ }^{3}$, Paschalis Alexandridis ${ }^{1}$, and Haiqing $\operatorname{Lin}^{1}{ }^{1} *$

${ }^{1}$ Department of Chemical and Biological Engineering, University at Buffalo, The State University of New York (SUNY), Buffalo, NY 14260, USA

${ }^{2}$ Department of Chemical and Biomolecular Engineering, University of Notre Dame, Notre

Dame, IN 46556, USA

${ }^{3}$ Cameron, Process Systems, Pittsburg Membrane R\&D, Verne Roberts Circle, Suite 102, Antioch, CA 94509, USA

*Corresponding author. Tel: +1-716-645-1856, Email: haiqingl@ buffalo.edu (H. Lin)

Revised manuscript to Polymer

$2 / 8 / 2016$ 


\begin{abstract}
Cellulose triacetate (CTA) is a workhorse polymeric membrane material for industrial $\mathrm{CO}_{2} / \mathrm{CH}_{4}$ separation. This study investigates the doping of CTA with ionic liquids (ILs) to reduce the crystallinity of the CTA and enhance its affinity with $\mathrm{CO}_{2}$, thus increasing $\mathrm{CO}_{2}$ permeability and $\mathrm{CO}_{2}$ /light gas selectivity. CTA films doped with 1-ethyl-3-methylimidazolium tetrafluoroborate $\left([\mathrm{emim}]\left[\mathrm{BF}_{4}\right]\right)$ and 1-ethyl-3-methylimidazolium dicyanamide ([emim][dca]) were prepared; and the effect of IL loading on properties of the CTA, such as crystallinity, density, degradation temperature, glass transition temperature, and gas transport properties, were determined. The IL doping reduces the glass transition temperature and degree of crystallinity of CTA, increasing gas diffusivity and permeability. The IL doping also increases $\mathrm{CO}_{2} / \mathrm{CH}_{4}$ solubility selectivity and $\mathrm{CO}_{2} / \mathrm{N}_{2}$ permeability selectivity, due to the affinity of these ILs with $\mathrm{CO}_{2}$, compared to light gases such as $\mathrm{CH}_{4}$ and $\mathrm{N}_{2}$. This study demonstrates a promising route in manipulating the morphology and gas transport properties of semi-crystalline polymers by doping with ILs.
\end{abstract}

Keywords: Cellulose triacetate; membrane $\mathrm{CO}_{2}$ separation; ionic liquids 


\section{Introduction}

Membrane technology has emerged as an important gas separation technology due to its inherent advantages such as small equipment footprint, easy maintenance, and high energy efficiency [1-3]. Polymeric membranes based on cellulose triacetate (CTA) have become the dominant choice for the removal of $\mathrm{CO}_{2}$ from natural gas for offshore applications, and they are emerging as a technology for onshore $\mathrm{CO}_{2}$ separations competitive with conventional technologies such as amine absorption [1-5]. As an off-the-shelf material, CTA is semi-crystalline, and the crystal domains are not accessible to gas sorption and diffusion, thus decreasing the $\mathrm{CO}_{2}$ solubility, diffusivity, and permeability [6-8]. The low $\mathrm{CO}_{2}$ permeability results in large membrane area required and thus relatively high capital and operation costs, which are partially ascribed to the prevention of the wide implementation of the membrane technology.

Numerous novel polymers have been designed and tailored for membrane $\mathrm{CO}_{2} / \mathrm{CH}_{4}$ separation, aiming to increase polymer size-sieving ability and thus $\mathrm{CO}_{2} / \mathrm{CH}_{4}$ diffusivity selectivity [9-14]. However, when exposed to real natural gas streams containing highly plasticizing components such as hexane and toluene, these polymers significantly sorb these hydrocarbons and thus lose size-sieving ability, leading to deteriorated $\mathrm{CO}_{2} / \mathrm{CH}_{4}$ separation performance $[15,16]$. CTA retains high performance for $\mathrm{CO}_{2} / \mathrm{CH}_{4}$ separation under practical operating conditions with heavy hydrocarbons present, largely due to its high $\mathrm{CO}_{2} / \mathrm{CH}_{4}$ solubility selectivity which may not be affected by the plasticization induced by the heavy hydrocarbons $[2,17]$. The high $\mathrm{CO}_{2} / \mathrm{CH}_{4}$ solubility selectivity in CTA can be further enhanced by lowering the operating temperature [18], though the polymer plasticization by the heavy hydrocarbons becomes more significant due to their increased solubility at lower temperatures. 
Various approaches have been explored to enhance the $\mathrm{CO}_{2} / \mathrm{CH}_{4}$ separation properties in CTA-based materials as a continuing effort to sharpen the competitiveness of the membrane technology. For example, liquid poly(ethylene glycol) has been added into CTA to form mixed matrix membranes [19] or polymer blends [20] to improve $\mathrm{CO}_{2} / \mathrm{CH}_{4}$ selectivity. Recently, cellulose acetate (CA) with hydroxyl groups was modified by grafting with vinyltrimethoxysilane and then cross-linking, leading to a modified CA containing 15 wt.\% element $\mathrm{Si}$ and an estimated 50 wt.\% CA [4]. The $\mathrm{CO}_{2}$ permeability increased from 5.0 Barrers for the neat CA to 139 Barrers for the modified one, presumably due to the decrease in crystallinity and increase in polymer chain flexibility [4]. However, the $\mathrm{CO}_{2} / \mathrm{CH}_{4}$ selectivity remained unchanged [4].

An alternative approach explored in this work is to dope CTA with ionic liquids (ILs). ILs are salts that are liquid at temperatures up to $100{ }^{\circ} \mathrm{C}$ with low vapor pressure and strong solvation ability for dissolving various organic and inorganic materials [14, 21-24]. ILs (such as imidazolium- and pyridinium-based ones) have also been extensively investigated for the dissolution of cellulosic materials $[25,26]$, since ILs can disrupt the hydrogen bonding in CTA and thus decrease the crystallinity [27-31]. More importantly, ILs have been extensively investigated for $\mathrm{CO}_{2} / \mathrm{CH}_{4}$ and $\mathrm{CO}_{2} / \mathrm{N}_{2}$ separation via absorption or membrane technology, due to the affinity between certain ILs and $\mathrm{CO}_{2}$ [32-39], leading to high $\mathrm{CO}_{2} / \mathrm{CH}_{4}$ and $\mathrm{CO}_{2} / \mathrm{N}_{2}$ solubility selectivity $[14,23,24,33,40]$. For example, the three typical polymers considered for $\mathrm{CO}_{2} / \mathrm{CH}_{4}$ separation, CTA, Matrimid ${ }^{\circledR} 5218$ polyimide [41], and cross-linked poly(ethylene oxide) [16], exhibit the $\mathrm{CO}_{2} / \mathrm{CH}_{4}$ selectivity of 9.1, 6.2 and 12 , respectively. The details are shown in Table S1 of the Supplemental Information. On the other hand, two common ILs, [emim] $\left[\mathrm{BF}_{4}\right]$ and [emim][dca], exhibit $\mathrm{CO}_{2} / \mathrm{CH}_{4}$ selectivity of about 20 , which is among the highest selectivity 
values for ILs studied [34]. Therefore, these two ILs are chosen in this study as dopants. The chemical structures of CTA and the two ILs are shown in Fig. 1. Although these ILs have been extensively used to blend with a variety of polymers to improve their gas separation properties [14, 24, 42-45], their doping with semi-crystalline CTA has not been studied yet.

(a) CTA

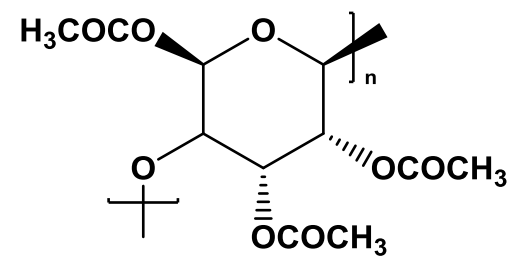

(b) $[\mathrm{emim}]\left[\mathrm{BF}_{4}\right]$

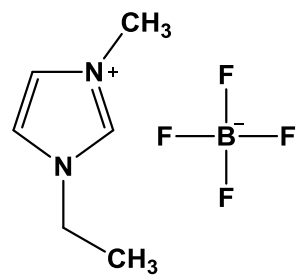

(c) $[\mathrm{emim}][\mathrm{dca}]$

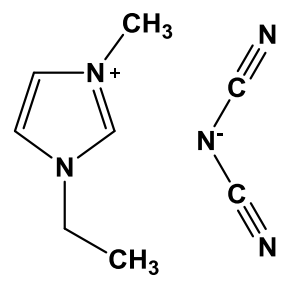

Fig. 1. Chemical structures of (a) cellulose triacetate (CTA), (b) $\left[\mathrm{emim}^{-}\left[\mathrm{BF}_{4}\right]\right.$, and (c) [emim][dca]. The CTA structure is simplified by omitting the residual hydroxyl groups considering the high degree of acetylation of 2.87 .

The objective of this work was to investigate the effects of the IL doping on the morphology and $\mathrm{CO}_{2} / \mathrm{CH}_{4}$ separation properties of CTA-based membranes. Two ILs were chosen, 1-ethyl-3methylimidazolium tetrafluoroborate $\left([\mathrm{emim}]\left[\mathrm{BF}_{4}\right]\right)$ and 1-ethyl-3-methylimidazolium dicyanamide ([emim][dca]), due to their high $\mathrm{CO}_{2} / \mathrm{CH}_{4}$ solubility selectivity [34]. The effect of the IL doping on polymer properties such as crystallinity, degradation temperature and glass transition temperature is determined. The pure-gas $\mathrm{CH}_{4}$ and $\mathrm{CO}_{2}$ solubility and $\mathrm{CH}_{4}, \mathrm{~N}_{2}$, and $\mathrm{CO}_{2}$ permeability were determined as a function of IL doping levels, and the gas diffusivity was calculated. These doped CTA materials were also evaluated for $\mathrm{CO}_{2} / \mathrm{N}_{2}$ separation due to the high $\mathrm{CO}_{2} / \mathrm{N}_{2}$ solubility selectivity in these ILs. This work provides a new route in modifying CTA to enhance its performance of $\mathrm{CO}_{2}$ removal from mixtures with light gases such as $\mathrm{CH}_{4}$ and $\mathrm{N}_{2}$. 


\section{Materials and experimental methods}

\subsection{Materials}

The CTA was provided by Cameron CYNARA ${ }^{\circledR}$ with a degree of acetylation of 2.87 and a molecular weight of $\sim 100,800 \mathrm{~g} / \mathrm{mole}$. $[\mathrm{Emim}]\left[\mathrm{BF}_{4}\right]$ and $[\mathrm{emim}][\mathrm{dca}]$ were purchased from IoLiTec Ionic Liquids Technology, Inc. (Tuscaloosa, AL) and used as received. Anhydrous dichloromethane $(>99.8 \%)$ and iso-octane (>99\%) were purchased from Aldrich Chemical Company (St. Louis, MO) and used as received. Pressurized gases of $\mathrm{CO}_{2}, \mathrm{CH}_{4}$ and $\mathrm{N}_{2}$ with ultrahigh purity (99.999\%) were purchased from Praxair Inc. (Tonawanda, NY).

\subsection{Preparation of thin films}

Thin films of IL-doped CTA were prepared by solvent casting as follows. CTA and IL in predetermined amounts were dissolved in dichloromethane, and the mixture was stirred overnight to form a homogeneous solution. The solution was then poured into a leveled glass petri dish. After drying in the air at ambient temperature overnight, the films were placed in a vacuum oven for $3 \mathrm{~h}$ at $65{ }^{\circ} \mathrm{C}$ to completely remove the dichloromethane (which has a boiling temperature of $40{ }^{\circ} \mathrm{C}$ ). The films were then stored at ambient temperature in a vacuum desiccator to avoid the sorption of water from the ambient. The prepared films have a thickness of $50-100 \mu \mathrm{m}$.

\subsection{Density measurement}

The density of the polymer films was determined via the buoyance method at room temperature using a Mettler-Toledo analytical balance (Model XS 64) equipped with a density 
kit. Iso-octane was used as the auxiliary liquid due to the negligible sorption in the polymers, and the polymer density, $\rho_{P}$, was calculated using eq. 1 as below [8]:

$\rho_{P}=\frac{M_{\text {air }}}{M_{\text {air }}-M_{\text {liquid }}}\left(\rho_{\text {air }}-\rho_{\text {liquid }}\right)+\rho_{\text {liquid }}$

where $M_{\text {air }}$ and $M_{\text {liquid }}$ are the weights of the film in air and in the auxiliary liquid, respectively. The $\rho_{\text {air }}$ and $\rho_{\text {liquid }}$ are the densities of air and the auxiliary liquid, respectively.

\subsection{X-ray diffraction and thermal analysis}

Wide-angle X-ray diffraction (WAXD) was conducted to evaluate the crystallinity of the IL-doped CTA films at room temperature. An Ultima IV X-ray diffractometer (Rigaku Corporation, Tokyo, JP) with a $\mathrm{Cu} \mathrm{K} \alpha$ radiation (wavelength of $1.54 \AA$ ) was used at a scan range of $5-40^{\circ}$ and a scan rate of $0.5^{\circ} / \mathrm{min}$. The degree of crystallinity was estimated using the Rigaku PDXL software by comparing the CTA/IL diffraction patterns to those of the CTA crystalline structure in the ICDD database and normalizing both the crystalline and amorphous peaks [46, 47].

Thermogravimetric analysis (TGA) was conducted using a TG 209 F1 (NETZSCH Group, Germany) in the temperatures range from $25^{\circ} \mathrm{C}$ to $600{ }^{\circ} \mathrm{C}$ with a heating rate of $10^{\circ} \mathrm{C} / \mathrm{min}$ under an argon flow rate of $40 \mathrm{~mL} / \mathrm{min}$. The degradation temperature was taken at the first derivative peak of the thermogravimetric curve using the Proteus Thermal Analysis software [48].

Thermal transitions in the polymer blends were determined using differential scanning calorimetry (DSC, Q2000, TA Instruments, New Castle, DE). The measurement was conducted at a heating rate of $20^{\circ} \mathrm{C} / \mathrm{min}$ under a nitrogen gas flow of $50 \mathrm{~mL} / \mathrm{min}$. The films were scanned in the range of $-80{ }^{\circ} \mathrm{C}$ to $300{ }^{\circ} \mathrm{C}$ for CTA, and $-80{ }^{\circ} \mathrm{C}$ to $200{ }^{\circ} \mathrm{C}$ for the IL-doped CTA. The highest temperature for the IL-doped CTA was set as $200{ }^{\circ} \mathrm{C}$ to avoid degradation during the 
scanning. The glass transition temperature was taken as the midpoint of the heat capacity step change using the Universal Analysis software from TA Instruments [49].

\subsection{Permeation and sorption measurement}

The pure-gas $\mathrm{N}_{2}, \mathrm{CH}_{4}$, and $\mathrm{CO}_{2}$ permeability values of the IL-doped CTA films were determined using a constant volume/variable pressure apparatus at $35^{\circ} \mathrm{C}$ [50]. Gas permeability was calculated from the steady-state rate of pressure increase in a fixed downstream volume [8, 50]. There appears no leakage of the ILs from the films onto the filter paper beneath after the IL-doped CTA samples were exposed to the high pressures.

The pure-gas $\mathrm{CO}_{2}$ and $\mathrm{CH}_{4}$ solubility values of the polymer films were measured using a gravimetric microbalance apparatus (IGA 001, Hiden Isochema, Warrington, UK) at $35{ }^{\circ} \mathrm{C}$ and pressures up to $14 \mathrm{~atm}$ [51]. The apparatus had a resolution of $0.1 \mu \mathrm{g}$, and the effect of buoyancy on the readings was considered using the Archimedes' principle. Polymer films of 60-100 mg with a thickness of $\sim 40 \mu \mathrm{m}$ were utilized. Prior to gas sorption measurements, the sample was dried and degassed for at least $8 \mathrm{~h}$ at $35{ }^{\circ} \mathrm{C}$ to remove all volatile impurities sorbed in the sample. Ultrahigh purity gas passed through a low temperature trap with a blend of liquid $\mathrm{N}_{2}$ and iso-octane (at $-107{ }^{\circ} \mathrm{C}$ ) to remove any possible contaminants before entering the sorption chamber [52]. Gas sorption at each pressure was deemed to have reached equilibrium once the microbalance reading remained unchanged for at least 30 minutes. The gas sorption was derived from the weight change of the polymer samples with a compensation of buoyancy effect [51, 52]. The uncertainty of gas permeability and solubility is estimated using an error propagation method and uncertainty for each determined parameter [53]. 


\section{Results and discussion}

\subsection{Morphology}

Figs. $2 \mathrm{a}$ and $2 \mathrm{~b}$ present representative WAXD spectra for CTA doped with [emim] $\left[\mathrm{BF}_{4}\right]$ and [emim][dca], respectively. Pure CTA exhibits two main peaks at $2 \theta=8^{\circ}$ and $17^{\circ}$, indicating the crystalline, and the amorphous phase of CTA, respectively $[6,54,55]$. In general, the WAXD peak intensity at $2 \theta=8^{\circ}$ for the CTA/IL blends decreases with increasing the IL content, indicating that the addition of IL reduces the CTA crystallinity.

(a)

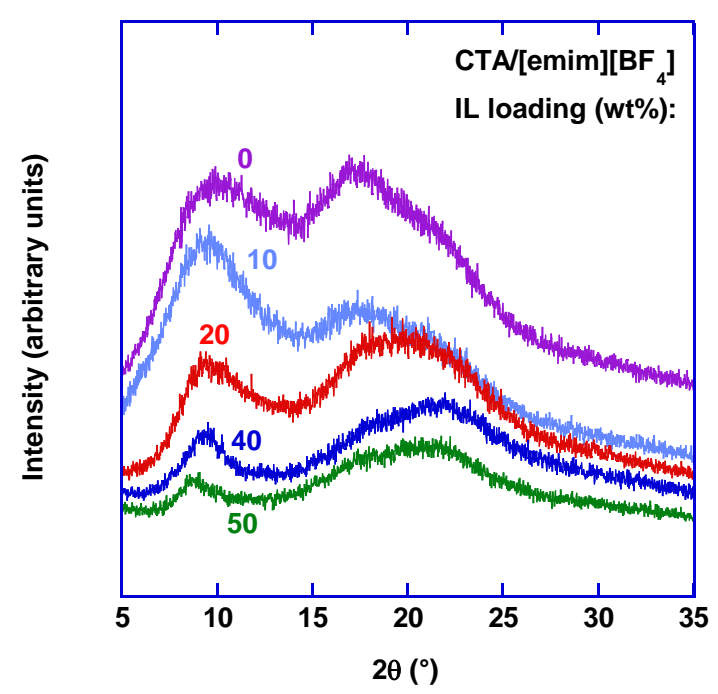

(b)

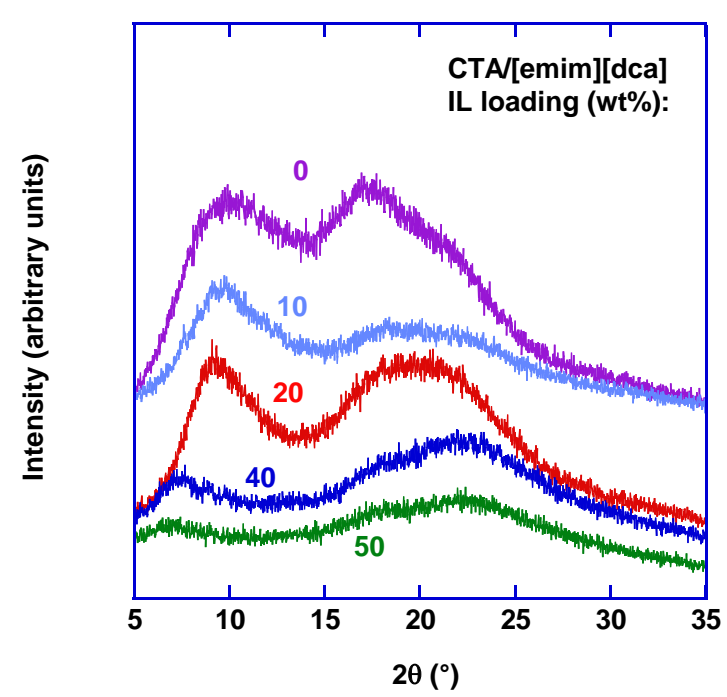

Fig. 2. X-ray diffraction patterns of CTA doped with (a) $[\mathrm{emim}]\left[\mathrm{BF}_{4}\right]$ and (b) [emim] [dca]. The numbers by the spectra indicate the overall IL weight percentage in the CTA/IL blends.

Table 1 summarizes the degree of crystallinity $\left(w_{c}\right)$ for the IL-doped CTA estimated by analyzing the WAXD patterns using the Rigaku PDXL software. [Emim][dca] is slightly more effective than $[\mathrm{emim}]\left[\mathrm{BF}_{4}\right]$ in disrupting the CTA crystallization. As the [emim][dca] content increases from $0 \mathrm{wt} \%$ to $50 \mathrm{wt} \%$, the crystallinity decreases from $28 \mathrm{wt} \%$ to $6.8 \mathrm{wt} \%$. At 10 wt\% IL loading, however, the CTA crystallinity increases, presumably because the IL may provide the polymer chains higher mobility for assembling and thus crystallization. Further 
increase in the IL content starts to decrease significantly the degree of crystallinity due to the CTA decrystallization and the IL dilution. The crystallization suppression of the CTA has been ascribed to the disruption of hydrogen bonds among the $\mathrm{OH}$, esters, and ether oxygen groups, which is critical for the CTA chains to pack efficiently and then crystallize [27-31].

\section{Table 1}

Density, degree of crystallinity $\left(w_{c}\right)$, amorphous phase IL weight fraction $\left(w_{a m, I L}\right)$ and volume fraction $\left(\phi_{a m, I L}\right)$ of the IL-doped CTA films at $22^{\circ} \mathrm{C}$

\begin{tabular}{|c|c|c|c|c|c|c|c|c|}
\hline \multirow{2}{*}{$\begin{array}{l}\text { IL } \\
\text { content } \\
(\mathrm{wt} \%)\end{array}$} & \multicolumn{4}{|c|}{ CTA/[emim] $\left[\mathrm{BF}_{4}\right]$} & \multicolumn{4}{|c|}{ CTA/[emim][dca] } \\
\hline & $\begin{array}{c}\rho_{P} \\
\left(\mathrm{~g} / \mathrm{cm}^{3}\right)\end{array}$ & $w_{c}$ & $w_{a m, I L}$ & $\phi_{a m, I L}$ & $\begin{array}{c}\rho_{P} \\
\left(\mathrm{~g} / \mathrm{cm}^{3}\right)\end{array}$ & $w_{c}$ & $w_{a m, I L}$ & $\phi_{a m, I L}$ \\
\hline 0 & 1.286 & 0.28 & 0 & 0 & 1.286 & 0.28 & 0 & 0 \\
\hline 10 & 1.293 & 0.37 & 0.16 & 0.16 & 1.288 & 0.32 & 0.15 & 0.16 \\
\hline 20 & 1.307 & 0.21 & 0.25 & 0.25 & 1.271 & 0.22 & 0.26 & 0.28 \\
\hline 40 & 1.313 & 0.13 & 0.46 & 0.45 & 1.231 & 0.11 & 0.45 & 0.48 \\
\hline 50 & 1.322 & 0.098 & 0.55 & 0.55 & 1.211 & 0.068 & 0.54 & 0.57 \\
\hline
\end{tabular}

Table 1 presents the composition of CTA and IL in the amorphous phase, assuming that the crystal phase is pure CTA and that the amorphous phase is a mixture of CTA and IL. This assumption is valid, since the characteristic peak for the crystalline phase in the blends is consistent with that of pure CTA. As expected, the IL content in the amorphous phase (i.e., $\left.w_{a m, I L}\right)$ is also higher than that in the overall films.

Table 1 also summarizes the density of the IL-doped CTA films. Since the blends are comprised of a crystalline CTA phase and an amorphous phase containing CTA and IL, the following equation can be derived based on the additive model $[8,56]$ :

$$
\frac{1}{1-w_{c}}\left(\frac{1}{\rho_{P}}-\frac{w_{c}}{\rho_{c}}\right)=\frac{1}{\rho_{a m, C T A}}+\left(\frac{1}{\rho_{I L}}-\frac{1}{\rho_{a m, C T A}}\right) w_{a m, \mathrm{IL}}
$$


where $\rho_{c}$ is the density of the crystalline CTA with a reported value $1.45 \mathrm{~g} / \mathrm{cm}^{3}$ [57], $\rho_{a m, C T A}$ is the density of the amorphous phase CTA with a reported value $1.24 \mathrm{~g} / \mathrm{cm}^{3}$ [57] and $\rho_{I L}$ is the IL density. The $\rho_{I L}$ value is $1.282 \mathrm{~g} / \mathrm{cm}^{3}$ for $[\mathrm{emim}]\left[\mathrm{BF}_{4}\right]$ and $1.101 \mathrm{~g} / \mathrm{cm}^{3}$ for [emim] [dca] at $20{ }^{\circ} \mathrm{C}$ [58]. As shown in Fig. S2 in the Supplementary Information, the density data can be well described by the model using eq. 2, corroborating the two-phase model in the IL-doped CTA (i.e., a crystalline CTA phase and an amorphous phase consisting CTA and IL).

Within the amorphous phase of the blends, the volume fraction of CTA $\left(\phi_{a m, I L}\right)$ can be expressed as:

$\phi_{a m, \mathrm{IL}}=\frac{w_{\mathrm{am}, \mathrm{LL}} / \rho_{\mathrm{IL}}}{w_{a m, C T A} / \rho_{a m, C T A}+w_{\mathrm{am}, \mathrm{LL}} / \rho_{\mathrm{IL}}}$

The results have been recorded in Table 1, which will be used later to correlate the gas transport properties of the blends with those of the individual components.

Fig. 3 shows the mass loss of the CTA/IL blends in the TGA runs with a temperature ramp rate of $10{ }^{\circ} \mathrm{C} / \mathrm{min}$. There is an initial weight loss at about $50{ }^{\circ} \mathrm{C}$, presumably due to loss of the remaining dichloromethane (with a boiling temperature of $40{ }^{\circ} \mathrm{C}$ ) in the blends. The estimated values of decomposition temperature $\left(T_{d}\right)$ and the corresponding weight loss are recorded in Table 2. The measured $T_{d}$ values of both pure CTA and the ILs are consistent with the literature findings $[6,55,59,60]$. Addition of the ILs clearly decreases the degradation temperature of CTA. These results suggest that the dissolved ILs disrupt the CTA chain packing, lowering the energy requirement to break the inter- and intra-bonding between polymer chains and rendering them more labile. It should be pointed out that the degradation behavior may change with the temperature ramp rate.

For the $\mathrm{CTA} /[\mathrm{emim}]\left[\mathrm{BF}_{4}\right]$ blends, the degradation occurs in two steps when the $[\mathrm{emim}]\left[\mathrm{BF}_{4}\right]$ loading is $20 \%$ or higher. The first degradation step is attributed to the degradation of CTA due 
to its lower $T_{d}$ value of $309^{\circ} \mathrm{C}$, and it is also confirmed by the weight loss of the first step. [Emim] $\left[\mathrm{BF}_{4}\right]$ seems to be able to partially disrupt the CTA chain packing, and the $T_{d}$ value decreases with increasing the $[\mathrm{emim}]\left[\mathrm{BF}_{4}\right]$ content. The second degradation step is attributed to the degradation of $[\mathrm{emim}]\left[\mathrm{BF}_{4}\right]$, since the second $T_{d}$ value is almost the same as that of pure $[\mathrm{emim}]\left[\mathrm{BF}_{4}\right]$

(a)

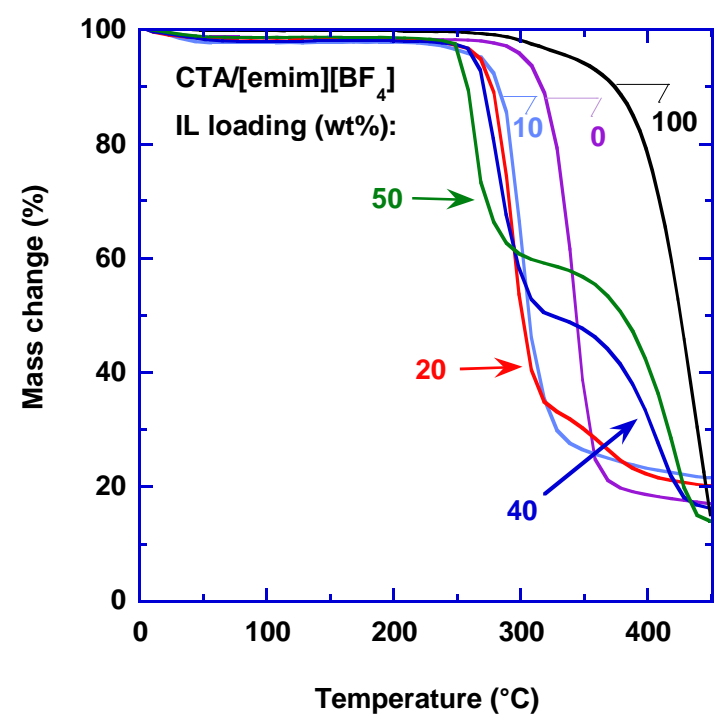

(b)

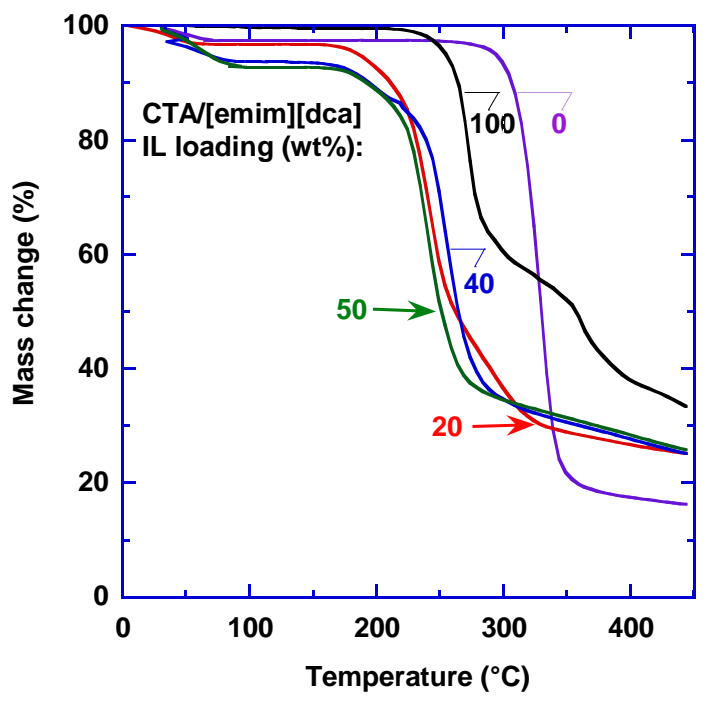

Fig. 3. TGA thermograms of CTA doped with (a) $[\mathrm{emim}]\left[\mathrm{BF}_{4}\right]$ and (b) $[\mathrm{emim}][\mathrm{dca}]$ with a temperature ramp rate of $10{ }^{\circ} \mathrm{C} / \mathrm{min}$. The numbers by the degradation curves denote the IL weight percentage in the blends.

Table 2

Glass transition temperature $\left(T_{g}\right)$, decomposition temperature $\left(T_{d}\right)$ and weight losses $\left(L_{1}\right.$ and $\left.L_{2}\right)$ at the $T_{d}$ 's of the CTA/IL blends

\begin{tabular}{|c|c|c|c|c|c|c|c|}
\hline \multirow{2}{*}{$\begin{array}{c}\mathrm{IL} \\
\text { content } \\
\text { (wt.\%) }\end{array}$} & \multicolumn{5}{|c|}{$\mathrm{CTA} /[\mathrm{emim}]\left[\mathrm{BF}_{4}\right]$} & \multicolumn{2}{|c|}{ CTA/[emim] [dca] } \\
\hline & $\begin{array}{c}T_{g} \\
\left({ }^{\circ} \mathrm{C}\right)\end{array}$ & $\begin{array}{l}1^{\mathrm{st}} T_{d} \\
\left({ }^{\circ} \mathrm{C}\right)\end{array}$ & $L_{1}(\%)$ & $L_{2}(\%)$ & $\begin{array}{c}\text { Measured } \\
w_{I L}\end{array}$ & $T_{g}\left({ }^{\circ} \mathrm{C}\right)$ & $T_{d}\left({ }^{\circ} \mathrm{C}\right)$ \\
\hline 0 & 198 & 309 & 86 & 0 & & 198 & 309 \\
\hline 10 & 113 & 289 & 70 & 7.4 & 0.09 & 111 & N/A \\
\hline 20 & 107 & 279 & 64 & 16 & 0.16 & 100 & 218 \\
\hline 40 & 45 & 268 & 46 & 37 & 0.43 & 55 & 219 \\
\hline 50 & 11 & 259 & 39 & 46 & 0.53 & -1 & 219 \\
\hline 100 & -92 & 412 & 83 & 0 & & -104 & 275 \\
\hline
\end{tabular}


Assuming that the first-step mass loss is for CTA only and the second step is for [emim] $\left[\mathrm{BF}_{4}\right]$ only, the following equation can be derived:

$$
w_{I L}=\frac{L_{2} / L_{I L}}{L_{1} / L_{C T A}+L_{2} / L_{I L}}
$$

where $L_{1}$ and $L_{2}$ are the mass loss at the $1^{\text {st }}$ and $2^{\text {nd }}$ degradation step, respectively. $L_{C T A}$ and $L_{I L}$ are the mass loss for the pure CTA and $[\mathrm{emim}]\left[\mathrm{BF}_{4}\right]$, respectively. As shown in Table 2, the compositions estimated from the TGA results are very close to that used for the preparation of the blends, validating the hypothesized degradation mechanism in the $\mathrm{CTA} /[\mathrm{emim}]\left[\mathrm{BF}_{4}\right]$ blends.

The $T_{d}$ values for the CTA/[emim][dca] blends are lower than those of the CTA/[emim][BF 4$]$ blends, suggesting that the dca ${ }^{-}$anion is more effective than $\mathrm{BF}_{4}^{-}$in interacting with CTA and thus affording decrystallization. The CTA/[emim][dca] blends have an almost constant $T_{d}$ value, while the CTA/[emim] $\left[\mathrm{BF}_{4}\right]$ blends show a decrease in the first $T_{d}$ decrease with increasing the IL loading.

As shown in Table 2, the increase in the IL loading decreases the $T_{g}$ value of the blends, suggesting an increase in the polymer chain mobility. The films become rubbery at the room temperature $\left(22^{\circ} \mathrm{C}\right)$ when the IL content is $50 \mathrm{wt} \%$. For the blends containing $40 \%$ and $50 \%$ [emim] $\left[\mathrm{BF}_{4}\right]$, two separate $T_{g}$ values are observed, indicating phase separation. Phase separation has also been reported in blends of poly(methyl methacrylate) and ILs [21]. For the CTA/[emim][dca] blends, there is only one $T_{g}$ at higher IL loading levels, suggesting that homogenous mixtures were obtained and that $[\mathrm{emim}][\mathrm{dca}]$ is more compatible with CTA than [emim] $\left[\mathrm{BF}_{4}\right]$. The detailed DSC curves are shown in Fig. S3 in the Supplemental Information.

The $w_{c}$ for the pristine CTA can be estimated by comparing the exothermic crystallization at around $220{ }^{\circ} \mathrm{C}$ and the endothermic melting at around $290{ }^{\circ} \mathrm{C}[6]$ : 
$w_{c}=\frac{\Delta H_{m}-\Delta H_{c}}{\Delta H_{\text {fusion }}}$

where $\Delta H_{m}(\mathrm{~J} / \mathrm{g})$ is the enthalpy of melting, $\Delta H_{c}(\mathrm{~J} / \mathrm{g})$ is the enthalpy of crystallization, and $\Delta H_{\text {fusion }}(\mathrm{J} / \mathrm{g})$ is the enthalpy of fusion (or melting) for a perfect CTA crystallite. $\Delta H_{\text {fusion }}$ has been estimated to be about $34.4 \mathrm{~J} / \mathrm{g}$ [6]. The obtained $w_{c}$ is 0.28 , which is consistent with that from the XRD characterization (0.28), as shown previously in Table 1.

The effect of the polymer blend composition on $T_{g}$ can be described using the Gordon-Taylor equation as shown below [61]:

$T_{g}=\frac{w_{a m, C T A} T_{g, \mathrm{CTA}}+K w_{a m, I L} T_{g, \mathrm{IL}}}{w_{a m, C T A}+K w_{a m, L L}}$

where $K$ is an adjustable parameter. Fig. 4 presents the best fitting of the $T_{g}$ values determined from DSC using eq. 6 with a $K$ value of 1.4 for $\mathrm{CTA} /[\mathrm{emim}]\left[\mathrm{BF}_{4}\right]$, and 1.5 for CTA/[emim][dca]. The data can be satisfactorily described by the model, considering the complicated morphology in these blends. In the fittings, the lower $T_{g}$ values for the blends containing $40 \%$ and $50 \%[\mathrm{emim}]\left[\mathrm{BF}_{4}\right]$ are used, with the assumption that the phase with the lower $T_{g}$ is dominant in the amorphous phase. The fitting results further corroborate this assumption. 


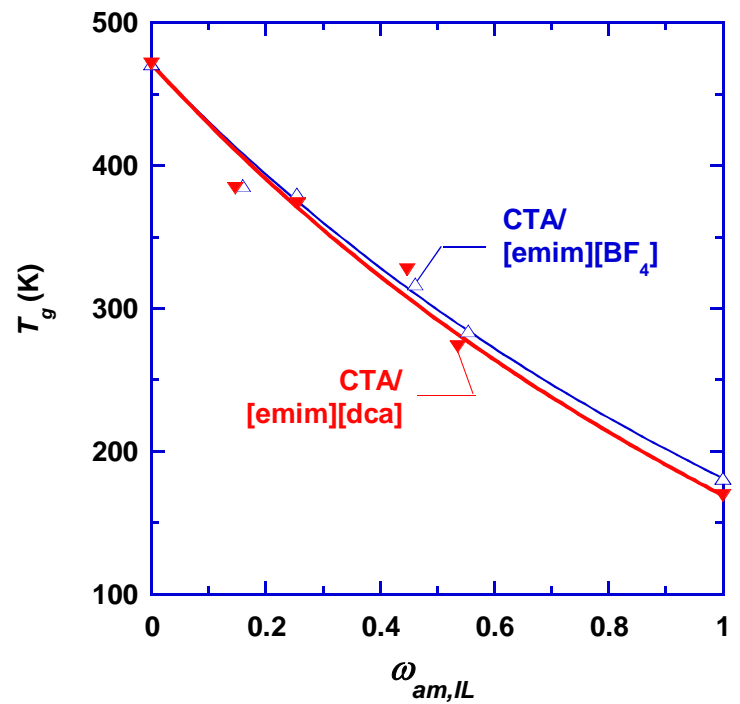

Fig. 4. Effect of the IL weight fraction in the amorphous phase $\left(w_{a m, I L}\right)$ on the glass transition temperature $\left(T_{g}\right)$ of the CTA/IL blends. The curves are best fittings based on eq. 6 with a $K$ value of 1.4 for $\mathrm{CTA} /[\mathrm{emim}]\left[\mathrm{BF}_{4}\right]$, and 1.5 for $\mathrm{CTA} /[\mathrm{emim}][\mathrm{dca}]$.

\subsection{Gas permeability of the CTA/IL blends}

Fig. 5 shows the pure-gas permeability at pressures of $4.4,7.8$, and 11.2 atm for the CTA/IL blends at $35{ }^{\circ} \mathrm{C}$. The permeability values have an uncertainty of $\pm 10 \%$ based on the error propagation analysis $[8,53]$, which was also confirmed by the measurement of multiple films. Both pure-gas $\mathrm{CH}_{4}$ and $\mathrm{N}_{2}$ permeability values are independent of the feed pressure, indicating that these polymer films are defect-free macroscopically. On the other hand, the pure-gas $\mathrm{CO}_{2}$ permeability increases with increasing pressures by as much as $33 \%$ and $26 \%$ for blends of $\mathrm{CTA} /[\mathrm{emim}]\left[\mathrm{BF}_{4}\right]$ and $\mathrm{CTA} /[\mathrm{emim}][\mathrm{dca}]$, respectively, largely due to the $\mathrm{CO}_{2}$ plasticization $[6$, 17]. The CTA doped with $10 \%$ IL shows lower permeability than the pristine CTA, presumably due to the higher crystallinity in the doped CTA. Further increase in the IL content increases the pure-gas permeability, presumably due to the reduced degree of crystallinity and the increased polymer chain mobility (or $T_{g}$ ), as shown in Tables 1 and 2 . 
(a)

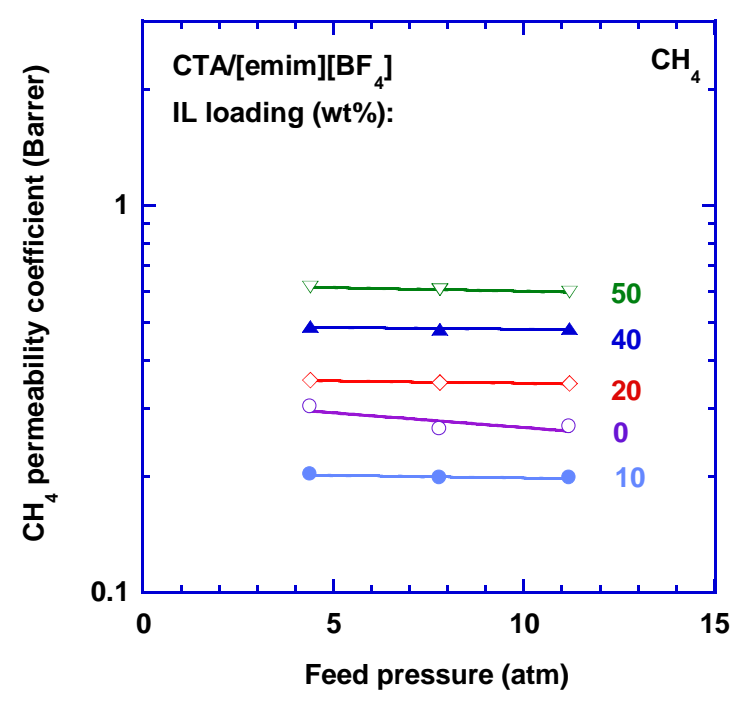

(c)

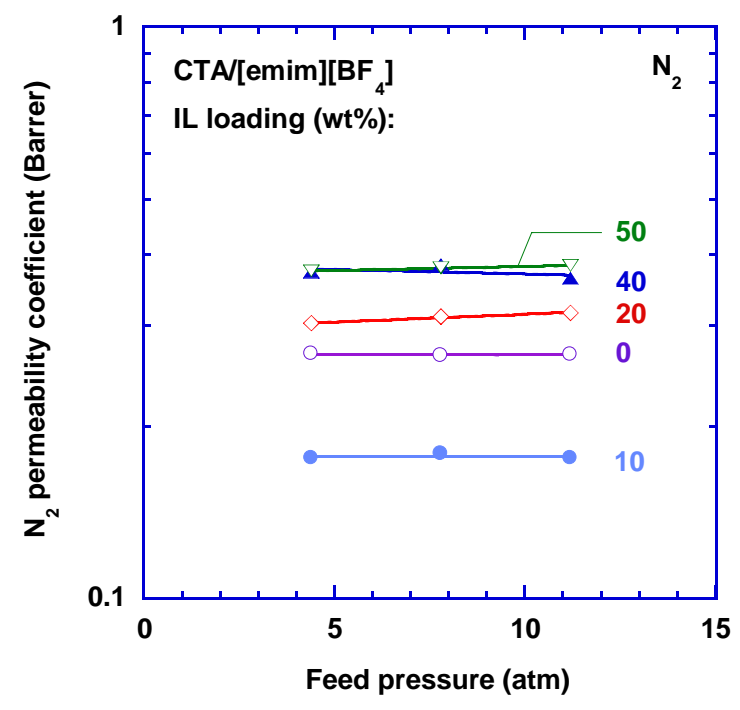

(b)

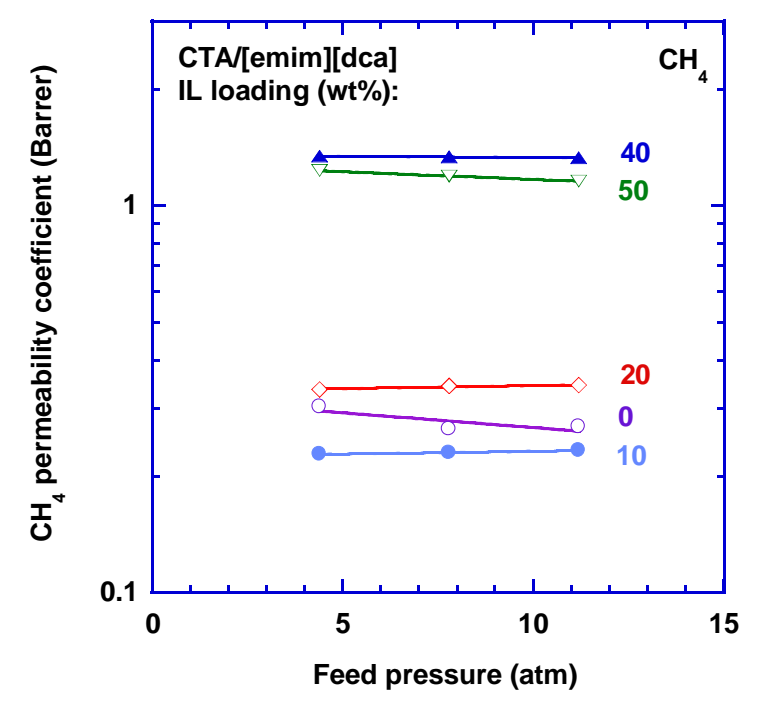

(d)

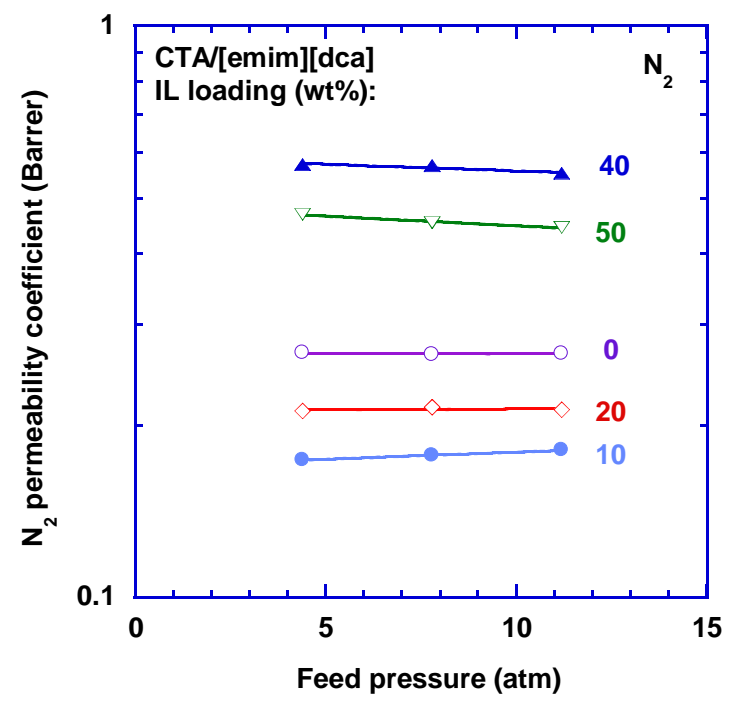


(e)

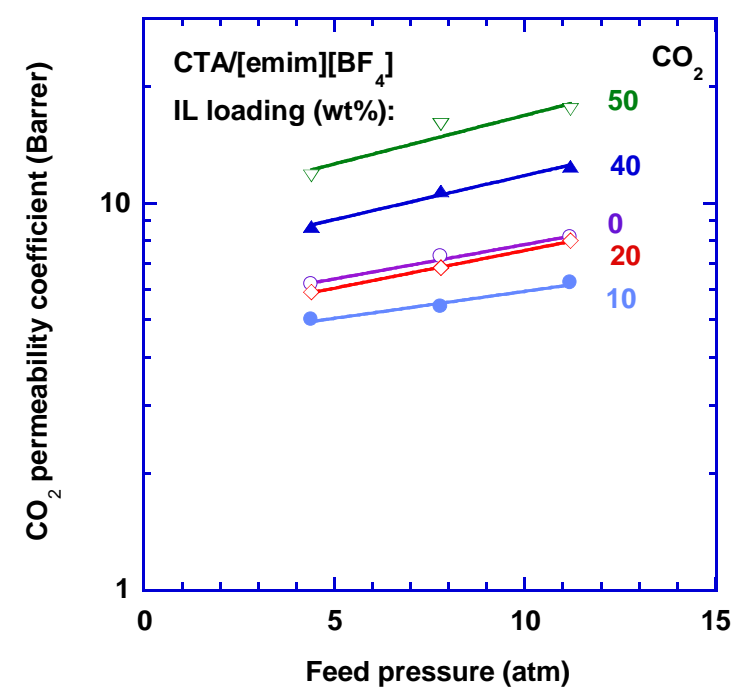

(f)

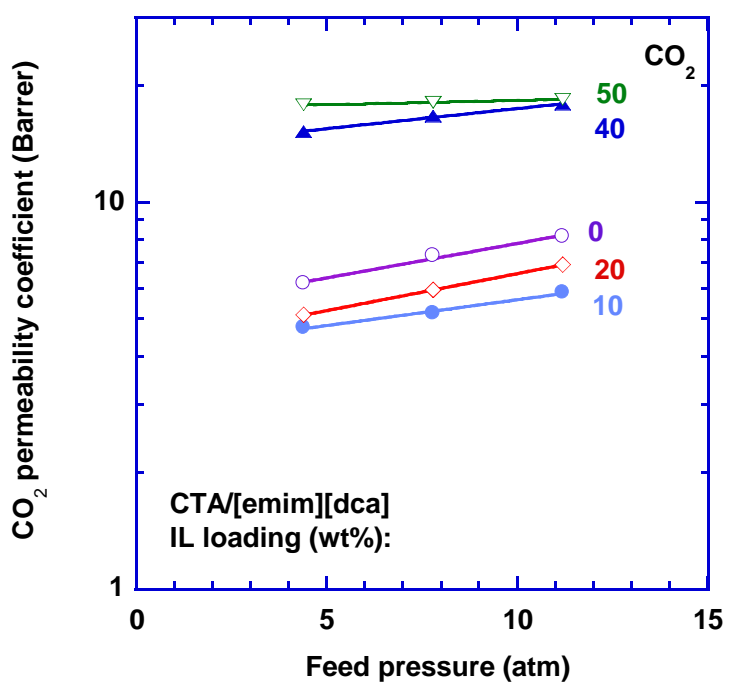

Fig. 5. Effect of feed gas pressure on pure-gas permeability at $35{ }^{\circ} \mathrm{C}$ : (a) $\mathrm{CH}_{4}$ in $\mathrm{CTA} /[\mathrm{emim}]\left[\mathrm{BF}_{4}\right]$; (b) $\mathrm{CH}_{4}$ in $\mathrm{CTA} /[\mathrm{emim}][\mathrm{dca}]$; (c) $\mathrm{N}_{2}$ in $\mathrm{CTA} /[\mathrm{emim}]\left[\mathrm{BF}_{4}\right]$; (d) $\mathrm{N}_{2}$ in $\mathrm{CTA} /[\mathrm{emim}][\mathrm{dca}]$; (e) $\mathrm{CO}_{2}$ in $\mathrm{CTA} /[\mathrm{emim}]\left[\mathrm{BF}_{4}\right]$; (f) $\mathrm{CO}_{2}$ in $\mathrm{CTA} /[\mathrm{emim}][\mathrm{dca}]$. The numbers by the lines indicate the IL weight percentage in the blends. 1 Barrer $=10^{-10} \mathrm{~cm}^{3}(\mathrm{STP}) \mathrm{cm} /\left(\mathrm{cm}^{2} \mathrm{~s}\right.$ $\mathrm{cmHg}$ ).

Gas permeability $\left(P_{A}\right)$ in nonporous polymers is usually expressed by eq 7 below [62]:

$$
P_{A}=S_{A} \times D_{A}
$$

where $S_{A}$ is the solubility coefficient and $D_{A}$ is the average effective diffusion coefficient through the film. For gas transport in semi-crystalline polymers, the crystalline domains are typically not accessible to penetrant sorption and diffusion, and the following equations are often used $[8,63$, 64]:

$$
\begin{aligned}
& S_{A, \mathrm{sc}}=S_{A, a m} \times \phi_{a m} \\
& D_{A, \mathrm{sc}}=D_{A, a m} \times \phi_{a m} \\
& P_{A, \mathrm{sc}}=P_{A, a m} \times \phi_{a m}^{2}
\end{aligned}
$$

where the subscript of "am" and "sc" indicates the properties in the wholly amorphous phase, and semi-crystalline polymers, respectively. 
Fig. 6 presents the estimated amorphous phase permeability, which can also be related to that of the individual components using the following equation $[65,66]$ :

$\ln P_{a m}=\phi_{a m, C T A} \ln P_{a m, C T A}+\phi_{a m, \mathrm{IL}} \ln P_{I L}$

where $P_{a m, C T A}$ and $P_{I L}$ are the gas permeability in the amorphous phase CTA and in IL, respectively. The fittings are generally good, despite the fact that the CTA/[emim] $\left[\mathrm{BF}_{4}\right]$ blends exhibit phase separation at higher $[\mathrm{emim}]\left[\mathrm{BF}_{4}\right]$ contents. This also corroborates that the phase with the lower $T_{g}$ value is dominant in the blends with phase separation.

(a)

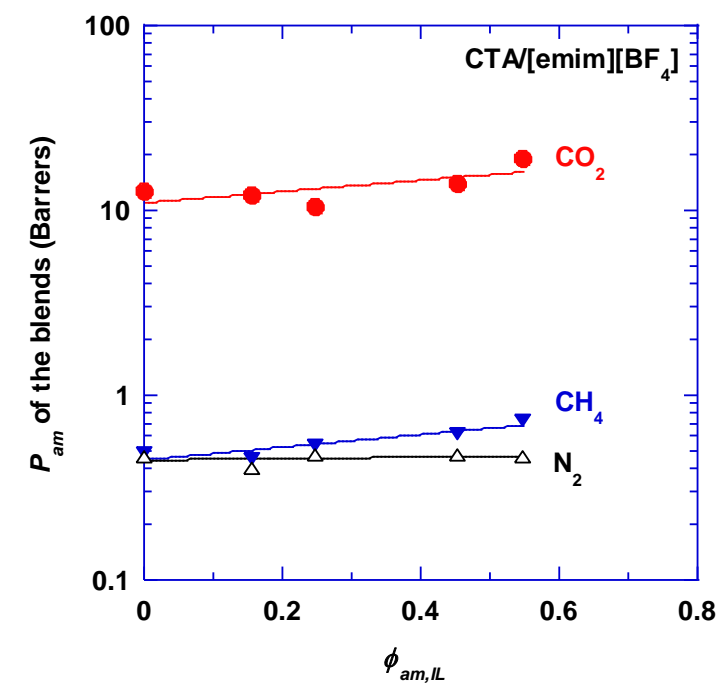

(b)

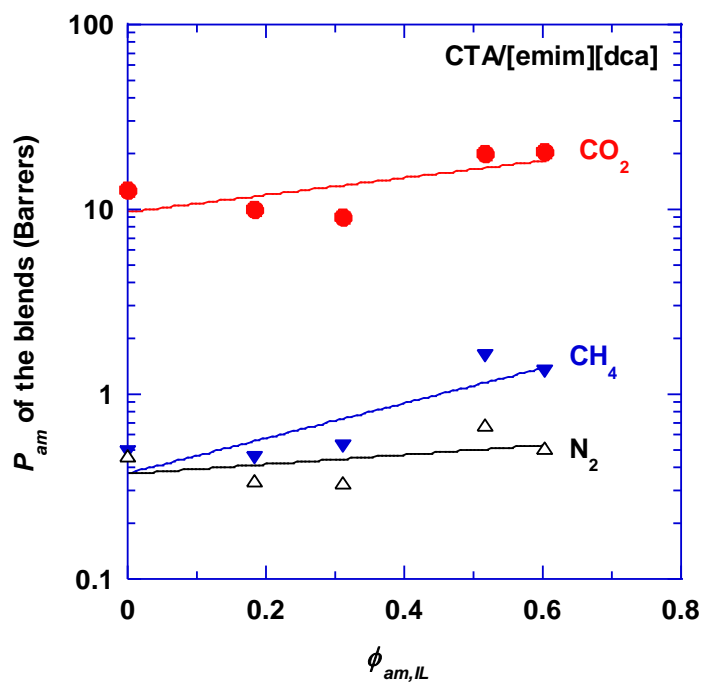

Fig. 6. Effect of the IL loading $\left(\phi_{a m, I L}\right)$ in the amorphous phase of the CTA/IL blends on the amorphous phase gas permeability in the CTA doped with (a) $\left[\mathrm{emim}^{\circ}\left[\mathrm{BF}_{4}\right]\right.$ and (b) [emim] [dca] at $35^{\circ} \mathrm{C}$ and $4.4 \mathrm{~atm}$. The lines are best fitting based on eq. 11.

Fig. 7 shows the effect of the IL volume fraction in the amorphous phase $\left(\phi_{a m, I L}\right)$ on the pure-gas selectivity in the amorphous phase blends. The doping of CTA with [emim][dca] decreases $\mathrm{CO}_{2} / \mathrm{CH}_{4}$ selectivity, while the doping with $[\mathrm{emim}]\left[\mathrm{BF}_{4}\right]$ decreases $\mathrm{CO}_{2} / \mathrm{CH}_{4}$ selectivity and then increases. Adding these two ILs in CTA leads to a trade-off between an increase in $\mathrm{CO}_{2} / \mathrm{CH}_{4}$ solubility selectivity and a decrease in $\mathrm{CO}_{2} / \mathrm{CH}_{4}$ diffusivity selectivity 
derived from the more flexible chains and weaker size-sieving ability. The different behavior in these two series of CTA/IL blends is caused by the more significant increase in solubility selectivity by the $[\mathrm{emim}]\left[\mathrm{BF}_{4}\right]$ doping than the $[\mathrm{emim}][\mathrm{dca}]$ doping, which will be described later. On the other hand, the $\mathrm{CO}_{2} / \mathrm{N}_{2}$ selectivity generally increases with increasing the IL content, presumably because the increase in $\mathrm{CO}_{2} / \mathrm{N}_{2}$ solubility selectivity is much more dominant than the decrease in diffusivity selectivity for both series of blends.

(a)

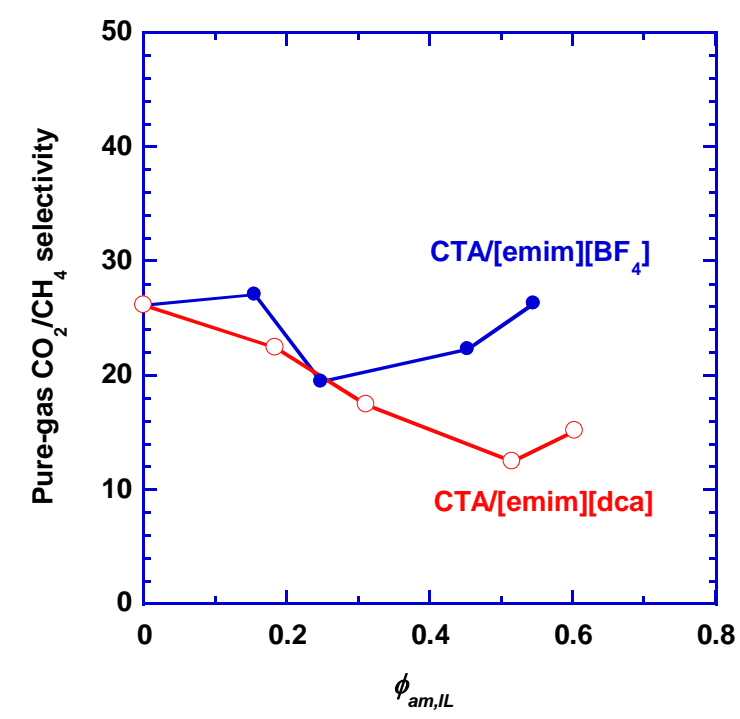

(b)

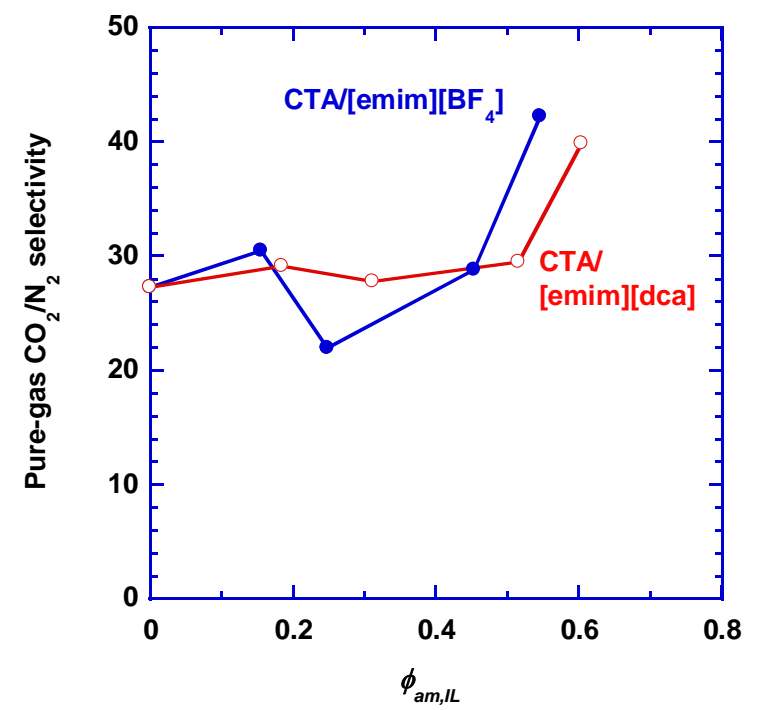

Fig. 7. (a) Effect of the IL volume fraction in the amorphous phase of the CTA/IL blends $\left(\phi_{a m, I L}\right)$ on (a) pure-gas $\mathrm{CO}_{2} / \mathrm{CH}_{4}$ selectivity and (b) $\mathrm{CO}_{2} / \mathrm{N}_{2}$ selectivity at $35^{\circ} \mathrm{C}$ and $4.4 \mathrm{~atm}$.

\subsection{Gas solubility in the CTA/IL blends}

Gas sorption in glassy polymers is usually described using a dual mode model, and gas concentration, $C_{A}\left(\mathrm{~cm}^{3}(\mathrm{STP}) / \mathrm{cm}^{3}\right.$ polymer), is given by eq. 12 below $[6,67,68]$ :

$C_{A}=k_{D, A} p_{A}+\frac{C_{H}^{\prime} b p_{A}}{1+b p_{A}}$

where $k_{D, A}\left(\mathrm{~cm}^{3}(\mathrm{STP}) / \mathrm{cm}^{3}\right.$ polymer atm $)$ is Henry's sorption coefficient, $C_{H}^{\prime}\left(\mathrm{cm}^{3}(\mathrm{STP}) / \mathrm{cm}^{3}\right.$ polymer) is the Langmuir capacity constant indicating the maximum sorption capacity of the 
non-equilibrium excess volume, and $b\left(\mathrm{~atm}^{-1}\right)$ is the Langmuir affinity of the gas. Rubbery polymers do not have Langmuir sorption sites and thus $C_{H}^{\prime}$ has a value of 0 [67].

Fig. 8 shows the pure-gas $\mathrm{CH}_{4}$ and $\mathrm{CO}_{2}$ sorption isotherms for CTA doped with the ILs at 35 ${ }^{\circ} \mathrm{C}$. The gas sorption has a uncertainty of $\pm 10 \%$ based on the error propagation analysis, which is also confirmed by the measurement using different samples. The sorption isotherms for pure CTA are in good agreement with those reported in the literature [6]. For the blends containing less than $50 \mathrm{wt} \% \mathrm{IL}$, the gas sorption isotherms are concave, which is typical for glassy polymers and can be described by the dual-mode sorption model $[6,67,69]$. The curves are the best fits by adjusting the sorption parameters in eq. 12 . As the IL loading increases to $50 \%$, the blends transition from glassy state to rubbery state and the isotherms become linear, which follows the Henry's sorption model for rubbery polymers [70]. 
(a)

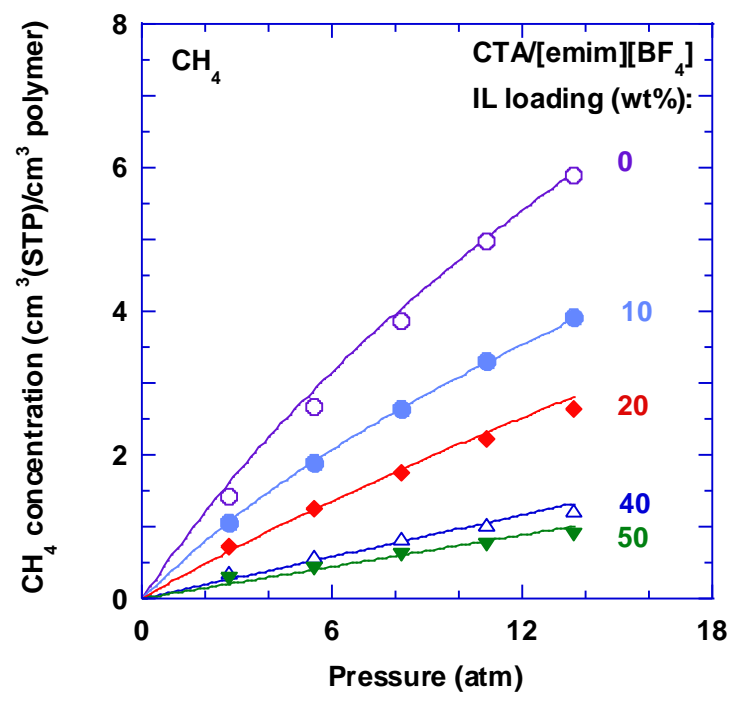

(c)

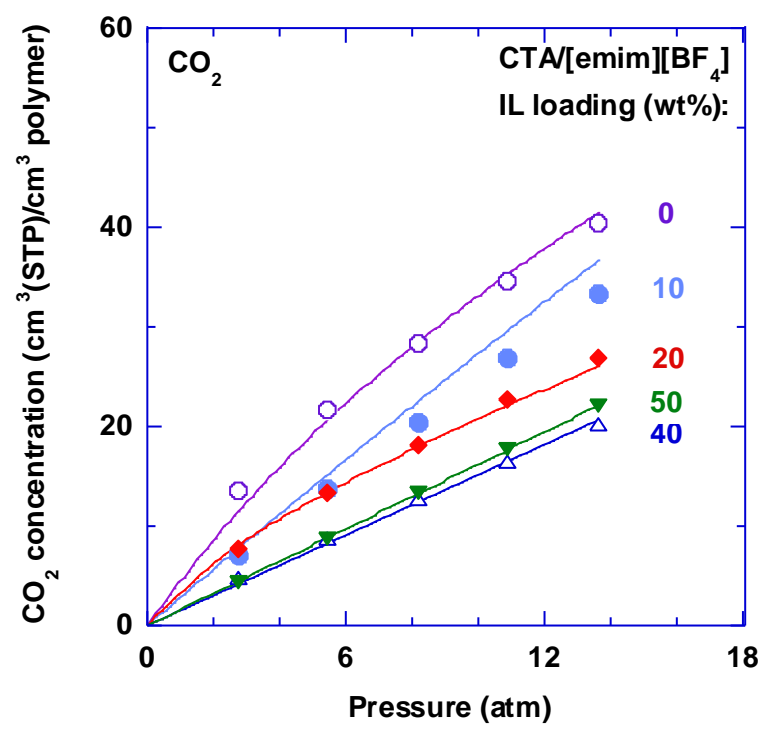

(b)

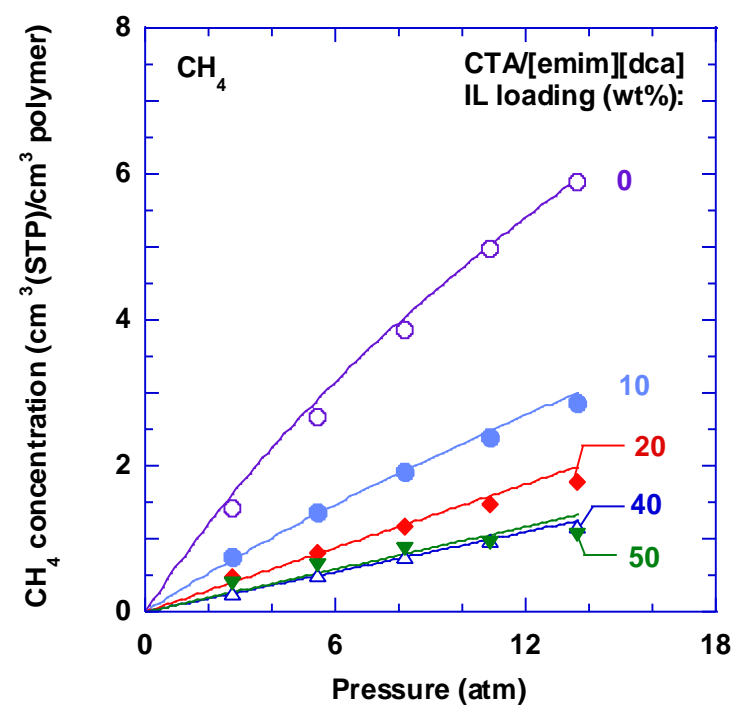

(d)

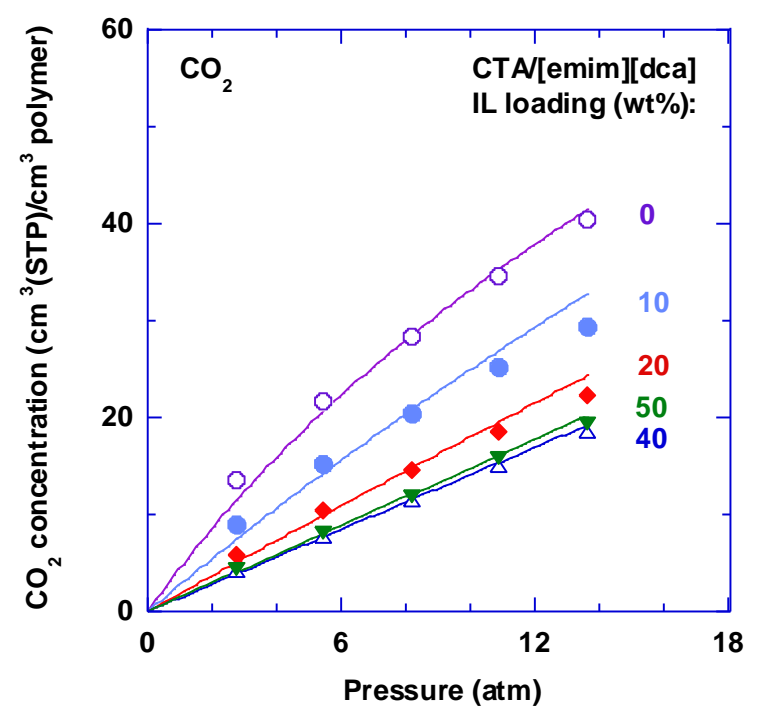

Fig. 8. Pure-gas sorption isotherms at $35{ }^{\circ} \mathrm{C}$ : (a) $\mathrm{CH}_{4}$ in $\mathrm{CTA} /[\mathrm{emim}]\left[\mathrm{BF}_{4}\right]$ blends; (b) $\mathrm{CH}_{4}$ in the $\mathrm{CTA} /[\mathrm{emim}][\mathrm{dca}]$ blends; (c) $\mathrm{CO}_{2}$ in the $\mathrm{CTA} /[\mathrm{emim}]\left[\mathrm{BF}_{4}\right]$ blends; (d) $\mathrm{CO}_{2}$ in the CTA/[emim][dca] blends. The curves are best fits using eq. 12. The numbers by the curves indicate the IL weight percentage in the blends.

Table 3 summarizes the sorption parameters modelled using the dual-mode sorption model (cf., eq. 12). The amorphous phase parameters $k_{D, a m}$ and $C_{H, a m}^{\prime}$ are calculated with an expression similar to eq. 8. In general, the $C_{H, a m}^{\prime}$ value decreases with increasing the IL loading and 
becomes zero when the IL loading is $40 \%$ or higher. This behavior is consistent with the gradual change from a glassy polymer containing Langmuir-type sorption sites to a rubbery polymer without Langmuir sorption sites (i.e., $C_{H, a m}^{\prime}=0$ ). As the IL loading increases, the $k_{D, a m}$ values slightly increase for $\mathrm{CO}_{2}$ and decrease for $\mathrm{CH}_{4}$, suggesting that the ILs exhibit more favorable $\mathrm{CO}_{2} / \mathrm{CH}_{4}$ solubility selectivity than CTA.

Table 3

Dual-mode sorption model parameters for the amorphous CTA/IL blends at $35^{\circ} \mathrm{C}$

\begin{tabular}{|c|c|c|c|c|c|c|c|}
\hline \multicolumn{2}{|c|}{ Composition } & \multicolumn{3}{|c|}{$\mathrm{CH}_{4}$} & \multicolumn{3}{|c|}{$\mathrm{CO}_{2}$} \\
\hline IL & $\phi_{a m, I L}$ & $k_{D, a m}{ }^{*}$ & $C_{H, a m}^{\prime}{ }^{\dagger}$ & $b\left(\mathrm{~atm}^{-1}\right)$ & $k_{D, a m}$ & $C_{H, a m}^{\prime}{ }^{\dagger}$ & $b\left(\mathrm{~atm}^{-1}\right)$ \\
\hline \multirow{5}{*}{$\begin{array}{l}{[\mathrm{emim}]} \\
{\left[\mathrm{BF}_{4}\right]}\end{array}$} & 0 & 0.25 & 4.1 & 0.15 & 1.5 & 22 & 0.22 \\
\hline & 0.16 & 0.20 & 4.3 & 0.11 & 1.6 & 15 & 0.19 \\
\hline & 0.25 & 0.18 & 1.9 & 0.075 & 1.6 & 11 & 0.33 \\
\hline & 0.45 & 0.11 & 0 & & 1.7 & 0 & \\
\hline & 0.55 & 0.081 & 0 & & 1.8 & 0 & \\
\hline \multirow{4}{*}{$\begin{array}{l}\text { [emim] } \\
\text { [dca] }\end{array}$} & 0.18 & 0.21 & 2.5 & 0.074 & 1.5 & 13 & 0.18 \\
\hline & 0.31 & 0.18 & 0.37 & 0.005 & 1.5 & 9.1 & 0.085 \\
\hline & 0.52 & 0.10 & 0 & & 1.6 & 0 & \\
\hline & 0.60 & 0.10 & 0 & & 1.6 & 0 & \\
\hline
\end{tabular}

Fig. 9 exhibits the effect of the IL loading on the pure-gas sorption of the amorphous polymer blends at $5.4 \mathrm{~atm}$ and $35{ }^{\circ} \mathrm{C}$. Gas solubility decreases with increasing ionic liquid content in the membrane, primarily because the blends transition from the glassy state with Henry and Langmuir sorption to the rubbery state with Henry's sorption only. CTA exhibits a $\mathrm{CO}_{2} / \mathrm{CH}_{4}$ solubility selectivity of 8.2 , which is very close to that of 9.0 , reported in the literature [6]. As the IL loading increases, the $\mathrm{CO}_{2} / \mathrm{CH}_{4}$ solubility selectivity increases, primarily due to the higher $\mathrm{CO}_{2} / \mathrm{CH}_{4}$ solubility selectivity in the ILs than in the CTA. [Emim][dca] exhibits a 
$\mathrm{CO}_{2} / \mathrm{CH}_{4}$ solubility selectivity of 18 , which is close to the value of 21 reported in the literature [34]. On the other hand, [emim] $\left[\mathrm{BF}_{4}\right]$ shows a $\mathrm{CO}_{2} / \mathrm{CH}_{4}$ selectivity of 41 in this study, which is much higher than that reported in the literature (20) [34], mainly because of the lower $\mathrm{CH}_{4}$ solubility measured in this study. $[\mathrm{Emim}]\left[\mathrm{BF}_{4}\right]$ possesses the smallest molar volume among ILs known [71]. Its gas sorption behavior can be sensitively affected by the third component in the systems $[71,72]$, presumably because the third component (CTA in this case) may disrupt the ionic interactions in the $[\mathrm{emim}]\left[\mathrm{BF}_{4}\right]$.

The gas solubility in the CTA/IL amorphous blends can also be related to that in the individual CTA and IL components using eq. 13 as shown below [65, 66]:

$\ln S_{a m}=\phi_{a m, C T A} \ln S_{a m, C T A}+\phi_{a m, \mathrm{IL}} \ln S_{I L}$

where $S_{a m, C T A}$ and $S_{, L}$ are the gas solubility for the amorphous phase CTA and IL, respectively. As shown in Figs. 9a and 9b, the gas solubility can be satisfactorily described by the equation. 
(a)

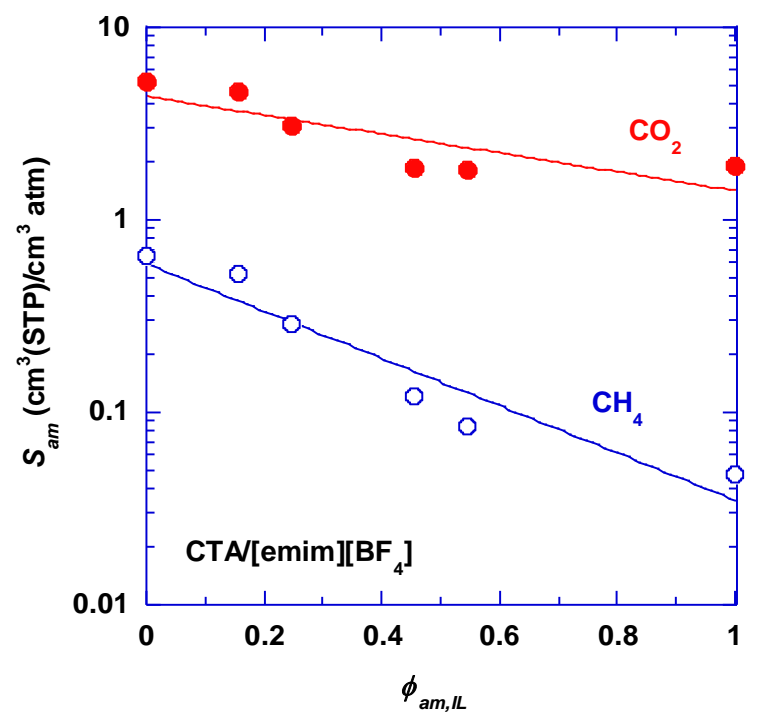

(c)

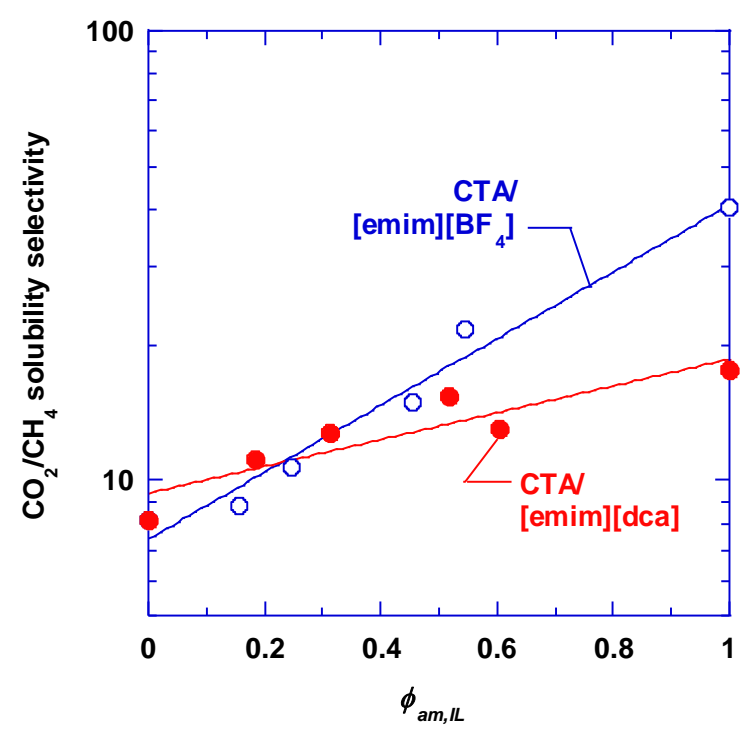

(b)

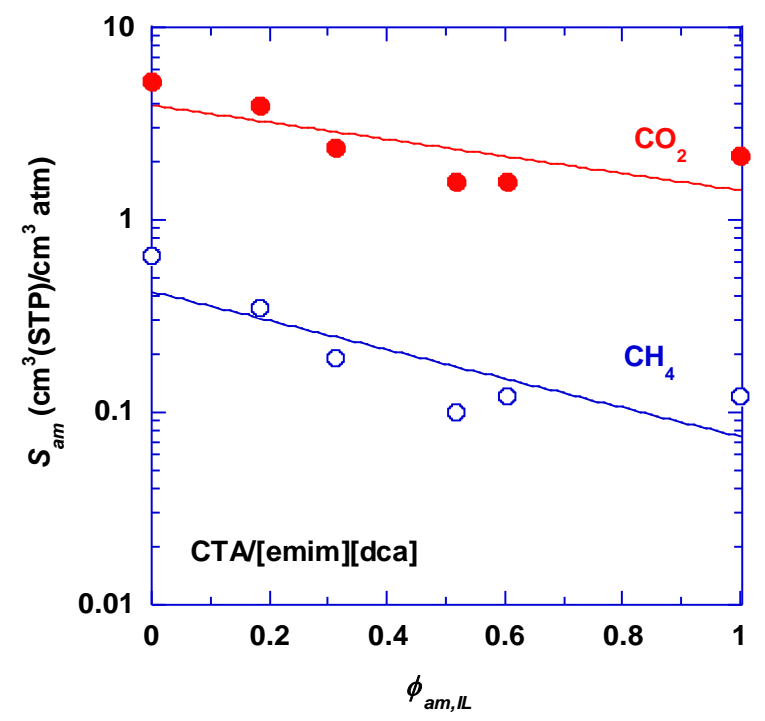

Fig. 9. Effect of the IL volume fraction in the amorphous phase CTA and IL $\left(\phi_{a m, C T A}\right)$ on $\mathrm{CO}_{2}$ and $\mathrm{CH}_{4}$ solubility in (a) the $\mathrm{CTA} /[\mathrm{emim}]\left[\mathrm{BF}_{4}\right]$ blends, and (b) the $\mathrm{CTA} /[\mathrm{emim}][\mathrm{dca}]$ blends; and (c) $\mathrm{CO}_{2} / \mathrm{CH}_{4}$ solubility selectivity. All values are for the amorphous phase at $35^{\circ} \mathrm{C}$ and 5.4 atm. The lines are best fits using eq. 13 .

\subsection{Gas diffusivity in the CTA/IL blends}

Fig. 10a illustrates the effect of the IL loading on the pure-gas $\mathrm{CO}_{2}$ diffusivity (cf. eq. 7 ) at $5.4 \mathrm{~atm}$ and $35^{\circ} \mathrm{C}$. In general, the diffusivity increases with increasing the IL loading in the amorphous phase polymer blends, due to the increase in the polymer chain flexibility, as 
indicated by the decreasing $T_{g}$ values. As shown previously in Table 2, the doping with [emim][dca] leads to more significant decrease in $T_{g}$ and therefore, higher $\mathrm{CO}_{2}$ diffusivity than that with $[\mathrm{emim}]\left[\mathrm{BF}_{4}\right]$, especially at the higher IL content.

As shown in Fig. 10b, the $\mathrm{CO}_{2} / \mathrm{CH}_{4}$ diffusivity selectivity is generally greater than 1 , due to the smaller molecular size of $\mathrm{CO}_{2}(3.3 \AA)$ than $\mathrm{CH}_{4}(3.8 \AA)$ [73]. As the IL content in the amorphous phase increases, the blends become more flexible and lose size-sieving ability, resulting in the decreased $\mathrm{CO}_{2} / \mathrm{CH}_{4}$ diffusivity selectivity. For example, pure CTA shows a $\mathrm{CO}_{2} / \mathrm{CH}_{4}$ diffusivity selectivity of 3.2 , while $\mathrm{CTA}$ doped with $\sim 55 \mathrm{wt} \%$ [emim] $\left[\mathrm{BF}_{4}\right]$ or [emim][dca] shows the $\mathrm{CO}_{2} / \mathrm{CH}_{4}$ diffusivity selectivity of only 1.2 , signifying the largely weakened size-sieving ability due to the glass-to-rubber transition at high IL loadings in these blends.

(a)

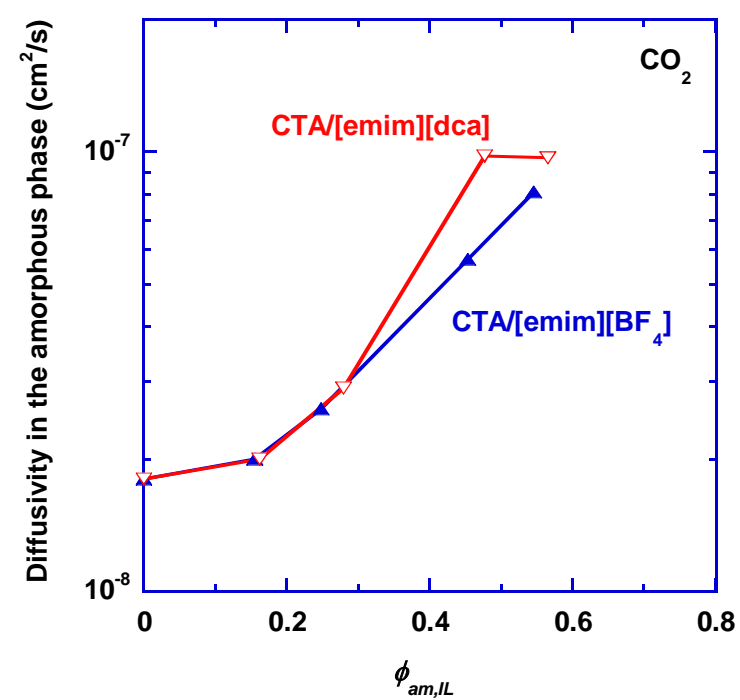

(b)

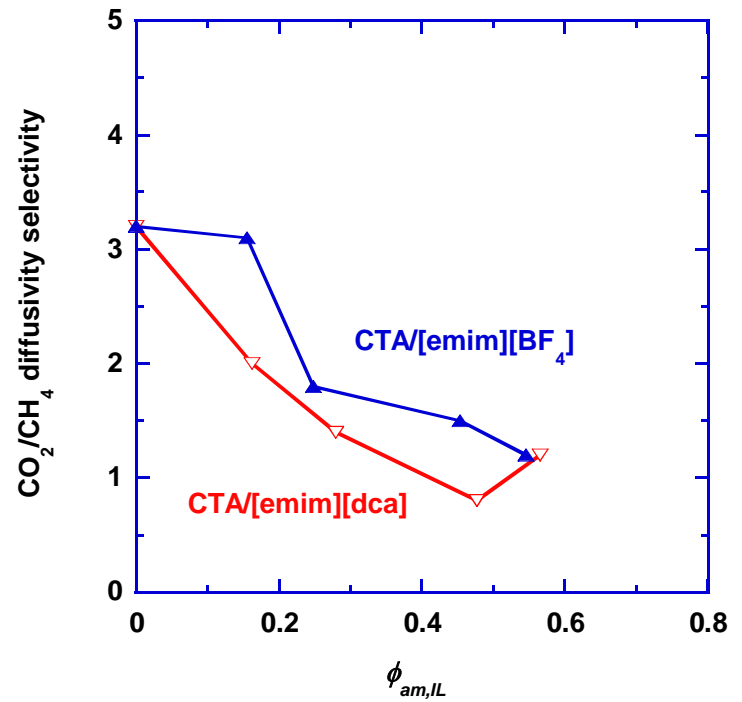

Fig. 10. Effect of the IL volume fraction in the amorphous phase $\left(\phi_{\text {am, IL }}\right)$ on (a) pure-gas $\mathrm{CO}_{2}$ diffusion coefficients and (b) $\mathrm{CO}_{2} / \mathrm{CH}_{4}$ diffusivity selectivity in the amorphous phase of CTA/IL blends at $5.4 \mathrm{~atm}$ and $35^{\circ} \mathrm{C}$. The lines are to guide the eye. 
As shown in the Supplemental Information (Table S2), the fractional free volume $(F F V)$ in the blends is estimated using the Bondi's group contribution method [23, 74]. There is no significant change in the $F F V$ of the blends as the IL loading increases from 0 to $\sim 50 \%$. On the other hand, the gas diffusivity increases by almost five fold while the $\mathrm{CO}_{2} / \mathrm{CH}_{4}$ diffusivity selectivity substantially decreases, which is caused by the increased polymer chain flexibility, instead of the changes in the FFV. This behavior has been observed. For example, tetramethyl polycarbonate (TMPC) with an $F F V$ of 0.180 has a $\mathrm{N}_{2}$ permeability of 1.1 Barrers at $35^{\circ} \mathrm{C}$ [75], while poly(dimethyl siloxane) (PDMS) has the same $F F V$ value $(0.180)$ and a $\mathrm{N}_{2}$ permeability of 400 Barrers, presumably due to its much lower $T_{g}\left(-120^{\circ} \mathrm{C}\right)[76]$.

\section{5. $\mathrm{CO}_{2} / \mathrm{CH}_{4}$ and $\mathrm{CO}_{2} / \mathrm{N}_{2}$ separation properties}

Fig. 11 compares the $\mathrm{CO}_{2} / \mathrm{CH}_{4}$ and $\mathrm{CO}_{2} / \mathrm{N}_{2}$ separation properties of these CTA/IL films with other materials represented in a Robeson's plot $[73,77,78]$. The upper bound line in a Robeson plot provides a rough estimate of the highest selectivity possible for a given collection of pure-gas permeability in polymer-based materials and this serves as a guideline for the development of new membrane materials $[73,77,78]$. The pure-gas permeation properties in the ILs were determined at low pressures with the ILs supported in porous supports, and they are near the upper bound lines [35]. For both $\mathrm{CO}_{2} / \mathrm{CH}_{4}$ and $\mathrm{CO}_{2} / \mathrm{N}_{2}$ separation, the doping of CTA with the ILs generally moves the separation properties closer to the upper bound, which demonstrates the effectiveness of the strategy in improving the CTA-based materials for membrane gas separation. The CTA/IL blends could be further optimized by identifying ILs with higher $\mathrm{CO}_{2} / \mathrm{CH}_{4}$ and $\mathrm{CO}_{2} / \mathrm{N}_{2}$ separation performance and higher efficiency in disrupting the crystallinity in the CTA than the two ILs studied here (i.e., $[\mathrm{emim}]\left[\mathrm{BF}_{4}\right]$ and $[\mathrm{emim}][\mathrm{dca}]$ ). 
(a)

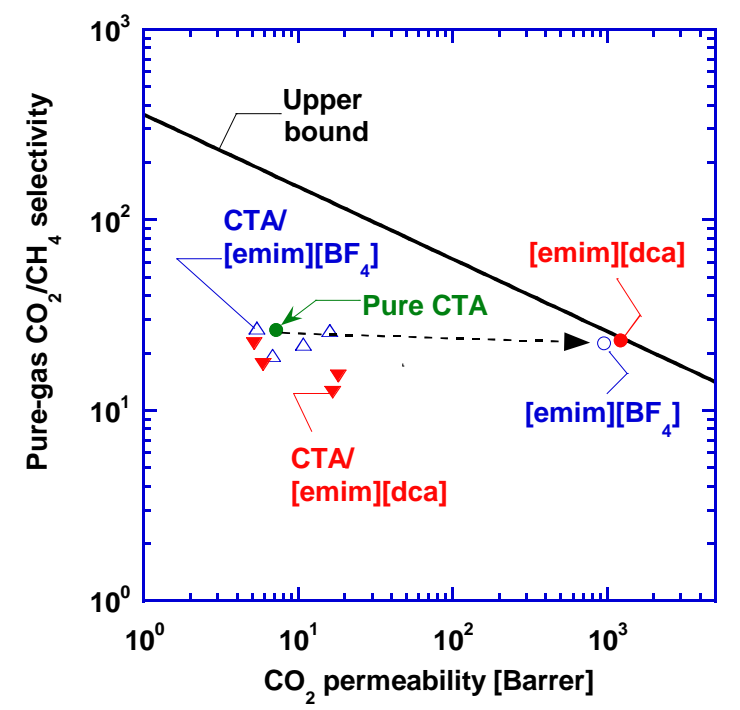

(b)

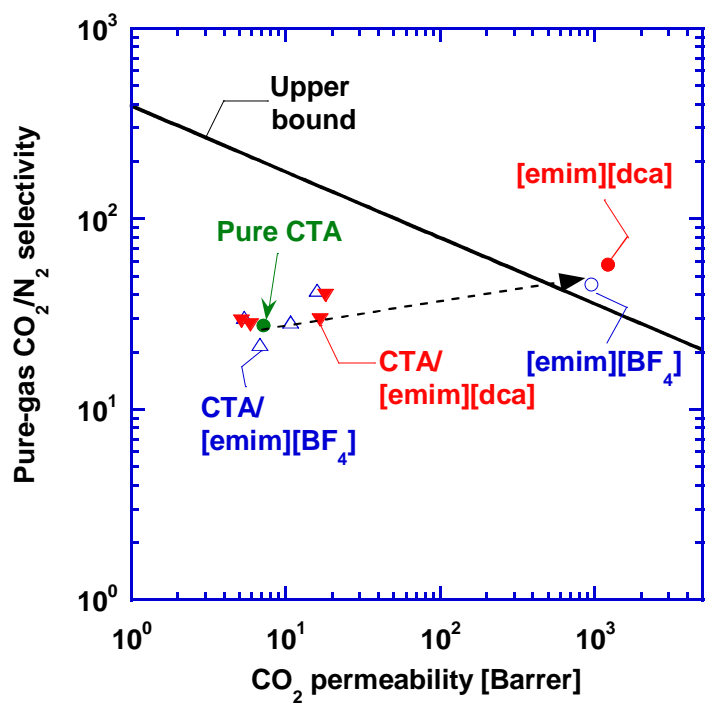

Fig. 11. Comparison of the CTA/IL blends with other materials for (a) $\mathrm{CO}_{2} / \mathrm{CH}_{4}$ separation and (b) $\mathrm{CO}_{2} / \mathrm{N}_{2}$ separation at $35^{\circ} \mathrm{C}$, as shown in Robeson plots $[73,77,78]$. The arrows indicate that the separation performance of the blends moves closer to the upper bound with adding ILs.

\section{Conclusion}

Although ILs have been widely explored for blending with membrane polymers to improve gas separation properties, this study for the first time aims to modify CTA, a workhorse membrane material for $\mathrm{CO}_{2} / \mathrm{CH}_{4}$ separation by doping with ILs. Doping with [emim] $\left[\mathrm{BF}_{4}\right]$ and [emim][dca] has been demonstrated here to be an effective way in disrupting the CTA crystallization, increasing gas diffusivity and permeability. The IL doping also decreases the degradation temperature and glass transition temperature. The blends become rubbery at the room temperature when the IL loading is $50 \mathrm{wt} \%$ or above. At an IL loading higher than $40 \%$, the CTA/[emim] $\left[\mathrm{BF}_{4}\right]$ blends exhibit two $T_{g}$ 's indicating a phase separation in the amorphous phase, while the CTA/[emim][dca] blends have only one single $T_{g}$, indicating that [emim][dca] is more compatible with CTA than [emim] $\left[\mathrm{BF}_{4}\right][79]$. 
Doping of CTA with the two ILs improves the $\mathrm{CO}_{2} / \mathrm{CH}_{4}$ and $\mathrm{CO}_{2} / \mathrm{N}_{2}$ solubility selectivity in the blends, due to the strong affinity between the ILs and $\mathrm{CO}_{2}$. For example, CTA exhibits a $\mathrm{CO}_{2} / \mathrm{CH}_{4}$ solubility selectivity of 9.1 at $35{ }^{\circ} \mathrm{C}$, whereas CTA doped with $55 \mathrm{wt} \%$ [emim] $\left[\mathrm{BF}_{4}\right]$ exhibits a $\mathrm{CO}_{2} / \mathrm{CH}_{4}$ solubility selectivity of 22 , which is among the highest selectivity reported for polymeric materials. On the other hand, IL doping of CTA decreases the $\mathrm{CO}_{2} / \mathrm{CH}_{4}$ diffusivity selectivity. Nevertheless, for both $\mathrm{CO}_{2} / \mathrm{CH}_{4}$ and $\mathrm{CO}_{2} / \mathrm{N}_{2}$ separation, the doping of CTA with the ILs moves the separation properties of the resulting blends toward Robeson's upper bound lines, which demonstrates the effectiveness of the approach in improving the $\mathrm{CO}_{2} /$ light gas separation properties by IL doping.

\section{Acknowledgments}

We gratefully acknowledge the financial support of this work from the Korean Carbon Capture and Sequestration R\&D Center and the New York State Center of Excellence in Materials Informatics at the University at Buffalo, The State University of New York. P.A. also acknowledges financial support from the U.S. National Science Foundation (award 1159981).

\section{References}

1. Baker RW and Lokhandwala K. Industrial \& Engineering Chemistry Research 2008;47:2109-2121. 
2. Lin H, White LS, Lokhandwala KA, and Baker RW. Natural gas purification. In: Hoek EMV and Tarabara VV, editors. Encyclopedia of Membrane Science and Technology. New Jersey: Wiley, 2013. pp. 1644-1667.

3. Sanders DE, Smith ZP, Guo RL, Robeson LM, McGrath JE, Paul DR, and Freeman BD. Polymer 2013;54(18):4729-4761.

4. Achoundong CSK, Bhuwania N, Burgess SK, Karvan O, Johnson JR, and Koros WJ. Macromolecules 2013;46(14):5584-5594.

5. $\quad$ Baker RW and Low B. Macromolecules 2014;47(20):6999-7013.

6. Puleo AC and Paul DR. Journal of Membrane Science 1989;47:301-332.

7. $\quad$ O'Leary KA and Paul DR. Polymer 2006;47(4):1226-1244.

8. $\quad$ Lin H and Freeman BD. Journal of Membrane Science 2004;239:105-117.

9. $\quad$ Wind JD, Staudt-Bickel C, Paul DR, and Koros WJ. Macromolecules 2003;36(6):18821888.

10. Park HB, Jung CH, Lee YM, Hill AJ, Pas JP, Mudie ST, Wagner EV, Freeman BD, and Cookson DJ. Science 2007;318:254-258.

11. $\mathrm{Ma} \mathrm{CH}$ and Koros WJ. Industrial \& Engineering Chemistry Research 2013;52(31):10495-10505.

12. Bos A, Punt IGM, Wessling M, and Strathmann H. Journal of Polymer Science. Part B: Polymer Physics 1998;36(9):1547-1556.

13. Xiao Y, Low BT, Hosseini SS, Chung TS, and Paul DR. Progress in Polymer Science 2009;34:561-580.

14. Dai Z, Noble RD, Gin DL, Zhang X, and Deng L. Journal of Membrane Science 2016;497:1-20.

15. White LS, Blinka TA, Kloczewski HA, and Wang I-F. Journal of Membrane Science 1995;103:73-82.

16. Lin H, Wagner EV, Raharjo R, Freeman BD, and Roman I. Advanced Materials 2006;18(1):39-44.

17. Lee SY, Minhas BS, and Donohue MD. AIChE Symposium Series 1988;84:93-101.

18. Sanders ES. Large Scale Membrane-based Gas Separations. North American Membrane Society Conference. Jackson Hole, WY, 2003.

19. Li NN, Funk EW, Chang YA, Kulkarni SS, Swamikannu AX, and White LS. Membrane Separation Processes in the Petrochemical Industry: Phase II, Final Report for U.S. Department of Energy, ID/12422-2. Des Plaines, IL: Allied-Signal, 1987.

20. Li J, Wang S, Nagai K, Nakagawa T, and Mau A. Journal of Membrane Science 1998;138(2):143-152.

21. Mok MM, Liu XC, Bai ZF, Lei Y, and Lodge TP. Macromolecules 2011;44(4):10161025.

22. He Z and Alexandridis P. Physical Chemistry Chemical Physics 2015;17:18238-18261.

23. Chen HZ, Li P, and Chung TS. International Journal of Hydrogen Energy 2012;37(16):11796-11804.

24. Jansen JC, Friess K, Clarizia G, Schauer J, and Izak P. Macromolecules 2011;44(1):3945.

25. Murakami M, Kaneko Y, and Kadokawa J. Carbohydrate Polymers 2007;69:378-381.

26. Wang H, Gurau G, and Rogers RD. Chemical Society Review 2012;41(4):1519-1537.

27. Pinkert A, Marsh KN, and Pang S. Industrial \& Engineering Chemistry Research 2010;49:11121-11130. 
28. Liu H, Sale KL, Holmes BM, Simmons BA, and Singh S. Journal of Physical Chemistry B 2010;114(12):4293-4301.

29. FitzPatrick M, Champagne P, and Cunningham MF. Cellulose 2012;19(1):37-44.

30. Ramesh S, R S, and Morris E. Carbohydrate Polymers 2012;87(4):2624-2629.

31. Xing DY, Peng N, and Chung TS. Journal of Membrane Science 2011;380(1-2):87-97.

32. Lodge TP. Science 2008;321(5885):50-51.

33. Bara JE, Camper DE, Gin DL, and Noble RD. Accounts of Chemical Research 2010;43(1):152-159.

34. Bara JE, Carlisle TK, Gabriel CJ, Camper D, Finotello A, Gin DL, and Noble RD. Industrial \& Engineering Chemistry Research 2009;48(6):2739-2751.

35. Scovazzo P. Journal of Membrane Science 2009;343(1-2):199-211.

36. Ramdin M, de Loos TW, and Vlugt TJH. Industrial \& Engineering Chemistry Research 2012;51(24):8149-8177.

37. Anderson JL, Dixon JK, and Brennecke JF. Accounts of Chemical Research 2007;40(11):1208-1216.

38. Cadena C, Anthony JL, Shah JK, Morrow TI, Brennecke JF, and Maginn EJ. Journal of American Chemical Society 2004;126(16):5300-5308.

39. Perdikaki AV, Vangeli OC, Karanikolos GN, Stefanopoulos KL, Beltsios KG, Alexandridis P, Kanellopoulos NK, and Romanos GE. Journal of Physical Chemistry C 2012;116(31):16398-16411.

40. Shahkaramipour N, Adibi M, Seifkordi AA, and Fazli Y. Journal of Membrane Science 2014;455:229-235.

41. Moore TT and Koros WJ. Journal of Applied Polymer Science 2007;104(6):4053-4059.

42. Gu YY, Cussler EL, and Lodge TP. Journal of Membrane Science 2012;423:20-26.

43. Hong SU, Park D, Ko Y, and Baek I. Chemical Communications 2009(46):7227-7229.

44. Kanehashi S, Kishida M, Kidesaki T, Shindo R, Sato S, Miyakoshi T, and Nagai K. Journal of Membrane Science 2013;430:211-222.

45. Bernardo P, Jansen JC, Bazzarelli F, Tasselli F, Fuoco A, Friess K, Izak P, Jarmarova V, Kacirkova M, and Clarizia G. Separation and Purification Technology 2012;97:73-82.

46. Jie X, Cao Y, and Yuan Q. Journal of Applied Polymer Science 2003;91:1873-1880.

47. Cabrales L, Abidi N, and Manciu F. Fibers 2014;2:285-294.

48. Li L, Zhang P, Liang J, and Guo SM. Ceramics International 2010;36:589-594.

49. Lin H, Wagner EV, Swinnea SJ, Freeman BD, Pas SJ, Hill AJ, Kalakkunnath S, and Kalika DS. Journal of Membrane Science 2006;276(1-2):145-161.

50. Lin H and Freeman BD. Permeation and Diffusion. In: Czichos H, Smith LE, and Saito T, editors. Springer-Handbook of Materials Measurement Methods: Springer, 2006. pp. 371-387.

51. Bahadur I, Osman K, Coquelet C, Naidoo P, and Ramjugernath D. Journal of Physical Chemistry B 2015;119(4):1503-1514.

52. Smith ZP, Tiwari RR, Murphy TM, Sanders DF, Gleason KL, Paul DR, and Freeman BD. Polymer 2013;54(12):3026-3037.

53. Bevington PR and Robinson DK. Data Reduction and Error Analysis for the Physical Sciences, 2nd ed. New York: McGraw-Hill, Inc., 1992.

54. Barud HS, de Araujo AM, Santos DB, de Assuncao RMN, Meireles CS, Cerqueira DA, Rodrigues G, Ribeiro CA, Messaddeq Y, and Ribeiro SJL. Thermochimica Acta 2008;471(1-2):61-69. 
55. Kamide K and Saito M. Polymer Journal 1985;17:919-928.

56. Maeda Y and Paul DR. Journal of Polymer Science. Part B: Polymer Physics 1987;25(5):1005-1016.

57. Sikorski P, Wada M, Heux L, Shintani H, and Stokke BT. Macromolecules 2004;37(12):4547-4553.

58. P. Li, Paul DR, and Chung TS. Green Chemistry 2012;14:12.

59. Huddleston JG, Visser AE, Reichert WM, Willauer HD, Broker GA, and Rogers RD. Green Chemistry 2001;3:156-164.

60. Sowmiah S, Srinivasadesikan V, Tseng MC, and Chu YH. Molecules 2009;14:37803813.

61. Gordon M and Taylor JS. Journal of Applied Chemistry 1952;2(9):493-500.

62. Wijmans JG and Baker RW. Journal of Membrane Science 1995;107(1-2):1-21.

63. Michaels AS and Bixler HJ. Journal of Polymer Science. Part A: Polymer Chemistry 1961;50:393-412.

64. Michaels AS and Bixler HJ. Journal of Polymer Science. Part A: Polymer Chemistry 1961;50:413-439.

65. Maeda Y and Paul DR. Polymer 1985;26(13):2055-2063.

66. Paul DR. Journal of Membrane Science 1984;18:75-86.

67. Koros WJ and Paul DR. Journal of Polymer Science. Part B: Polymer Physics 1978;16(11):1947-1963.

68. Maeda Y and Paul DR. Journal of Polymer Science. Part B: Polymer Physics 1987;25(5):957-980.

69. Matteucci; S, Yampolskii; Y, Pinnau; I, and Freeman; BD. Transport of Gases and Vapors in Glassy and Rubbery Polymers. In: Yampolskii; Y, Pinnau; I, and Freeman; BD, editors. Materials Science of Membranes for Gas and Vapor Separations: John Wiley \& Sons, Ltd, 2006. pp. 1-48.

70. Koros WJ and Paul DR. Journal of Polymer Science: Polymer Physics Edition 1978;16:1947.

71. Finotello A, Bara JE, Narayan S, Camper D, and Noble RD. Journal of Physical Chemistry B 2008;112(8):2335-2339.

72. Shannon MS, Tedstone JM, Danielsen SPO, Hindman MS, Irvin AC, and Bara JE. Industrial \& Engineering Chemistry Research 2012;51(15):5565-5576.

73. Freeman BD. Macromolecules 1999;32(2):375-380.

74. Van Krevelen DW. Properties of Polymers: Their Correlation with Chemical Structure: Their Numerical Estimation and Prediction from Additive Group Contributions. Amsterdam: Elsevier, 1990.

75. Pixton MR and Paul DR. Relationships between structure and transport properties for polymers with aromatic backbones. In: Paul DR and Yampol'skii YP, editors. Polymeric Gas Separation Membranes. Boca Raton, FL: CRC Press, Inc., 1994. pp. 83-154.

76. Merkel TC, Bondar VI, Nagai K, Freeman BD, and Pinnau I. Journal of Polymer Science: Part B: Polymer Physics 2000;38:415-434.

77. Robeson LM. Journal of Membrane Science 2008;320:390-400.

78. Lin H and Yavari M. Journal of Membrane Science 2015;475:101-109.

79. $\quad \mathrm{Xu} \mathrm{A}$, Wang J, and Wang H. Green Chemistry 2010;12:8. 